ISSN: 1641-4713; e-ISSN: 2081-1160

DOI: https://doi.org/10.36551/2081-1160.2021.27.193-228

\title{
Autopercepciones de clase e identificaciones políticas en un barrio ferroviario del conurbano bonaerense
}

\author{
Class Self-perceptions and political identifications in a railway district \\ of the Buenos Aires suburbs
}

Silvina Merenson

Consejo Nacional de Investigaciones Científicas y Técnicas/Escuela IDAES

Universidad Nacional de San Martín, Argentina ORCID iD: https://orcid.org/0000-0002-2614-0541

E-mail: smerenson@unsam.edu.ar

Menara Guizardi

Consejo Nacional de Investigaciones Científicas y Técnicas/Escuela IDAES

Universidad Nacional de San Martín, Argentina

Universidad de Tarapacá, Chile

ORCID iD: https://orcid.org/0000-0003-2670-9360

E-mail: menaraguizardi@yahoo.com.br

Recepción: 16.01.2021

Aprobación: 26.05.2021

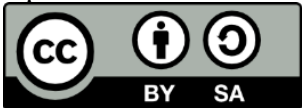

Resumen: El artículo analiza las relaciones entre las autopercepciones de clase y las identificaciones políticas en Barrio Operario, un vecindario ferroviario situado en el municipio de San Isidro, sector norte del conurbano de Buenos Aires (Argentina). Siguiendo una estrategia metodológica interdisciplinaria nos detendremos en tres periodos: su origen y organización ligados a la "estrategia justicialista" de desarrollo (1945-1955); su paulatino pero sostenido devenir como "villa miseria", asociado fundamentalmente a la "estrategia aperturista" (1976-2002); y, finalmente, su urbanización desde 2003, en el marco de la "sociedad posneoliberal". Destinaremos un acápite a cada uno de ellos, antecedido por una reseña de las contribuciones que, desde los abordajes sociológicos, históricos y etnográficos permitieron comprender las configuraciones de clase y sus identificaciones políticas.

Palabras clave: Argentina, autopercepción de clase, estructura social, identificación política, etnografia. 


\begin{abstract}
The article analyzes the relationships between self-perceptions of class and political identifications in Barrio Operario, a railway district located in the municipality of San Isidro, in the northern suburbs of Buenos Aires (Argentina). Following an interdisciplinary methodological framework, we will dwell on three periods: the neighborhood origin and organization linked to the "Justicialist strategy" of development (1945-1955); its gradual but sustained evolution as a "slum", fundamentally associated with Argentina's "opening strategy" (1976-2002) and, finally, its urbanization since 2003, within the framework of the "post-neoliberal society". We will allocate a section to each one of them, preceded by a review of the contributions that, from the sociological, historical, and ethnographic approaches, allowed us to understand the class configurations and their political identifications.
\end{abstract}

Keywords: Argentina, self-perception of class, social structure, political identification, ethnography.

\title{
INTRODUCCIÓN ${ }^{1}$
}

Este texto analiza en perspectiva histórica las relaciones entre las identificaciones políticas y las autoadscripciones de clase. Para ello abordamos las conexiones entre las nociones de "posición" y "situación" de clase, buscando interpretar procesos de desigualdad y diferenciación integrando aspectos objetivables, simbólicos y relacionales. Nuestro análisis centraliza la experiencia situacional y contextualizada de la clase como una configuración, es decir como conflicto habilitado por una lectura multilineal del proceso histórico.

Exploraremos diferentes posiciones, estructuras, autopercepciones, dinámicas, ritmos de cambios y continuidades que dialogan de formas heterogéneas con distintos posicionamientos políticos en Barrio Operario, ${ }^{2}$ un vecindario ferroviario situado en el municipio de San Isidro, sector norte del conurbano de Buenos Aires (Argentina). Concretamente, rastrearemos las dinámicas de la experiencia de las clases y las identificaciones políticas, correlacionando las formas que asumen estos vínculos con factores macrosociales, macropolíticos y macroeconómicos. Nos detendremos en tres periodos en los que esta correlación mostró incidencia entre sus vecinos y vecinas: su origen y organización ligados a la "estrategia justicialista" de desarrollo (Torrado, 2010), desde fines de los cuarenta hasta mediados de la década siguiente; su paulatino pero sostenido devenir como "villa miseria" (Guber, 1991) asociado fundamentalmente a la "estrategia aperturista"; y, finalmente, su urbanización desde 2003 en el marco de una sociedad descrita como "posneoliberal" (Kessler, 2016). Destinaremos un acápite a cada uno de ellos, antecedido por una reseña de las contribuciones que, desde los

\footnotetext{
${ }^{1}$ Las autoras agradecen a la Agencia Nacional de Promoción Científica y Tecnológica de Argentina que financia el estudio que da origen a este artículo a través del proyecto PICT 2017-1767, "Clases medias emergentes de Argentina, Brasil y Uruguay: Autoidentificación y nuevos horizontes".

${ }^{2}$ Para resguardar los criterios éticos de la investigación el nombre del barrio no obedece al real.
} 
abordajes sociológicos, históricos y etnográficos permitieron comprender las configuraciones de los sectores populares y las clases medias urbanas y sus identificaciones políticas en el conurbano bonaerense.

El trabajo de campo en Barrio Operario, iniciado en octubre de 2019, se desplegó a partir de tres estrategias interdisciplinarias. La primera incluyó la realización de observaciones etnográficas y el sostenimiento de múltiples interacciones y conversaciones informales con sus residentes registradas en diarios de campo. Esto permitió construir los accesos al campo, tener una primera idea de los distintos grupos sociales que integran el barrio y cartografiar sus diversos espacios, bordes y límites. La segunda consistió en la aplicación de un instrumento cuantitativo diseñado a partir de los ejes temáticos y preguntas de la Encuesta Nacional de Estructura Social (ENES) del Programa de Investigación sobre la Sociedad Argentina Contemporánea (PISAC). ${ }^{3}$ La encuesta, aplicada a 22 personas (10 mujeres y 12 varones), consideró el tiempo y la zona de residencia en el barrio, además de la distribución por edad y sexo. La tercera fue la recopilación de la historia de vida de 17 personas (9 varones y 8 mujeres) en entrevistas registradas con grabadora digital, posteriormente transcriptas, codificadas y analizadas con apoyo del Software MaxQDA. Estas buscaron captar la heterogeneidad controlada que habita Barrio Operario cuando se trata de narrativas biográficas y familiares respecto de las autopercepciones y de relatos sobre los horizontes, consumos, valores, sentidos comunes y sus modulaciones políticas.

\section{CLASES SOCIALES E IDENTIFICACIONES POLÍTICAS}

Desde los años setenta, en parte de la historiografía sobre la clase obrera en Argentina, rondó una pregunta -los orígenes del peronismo- y una impugnación -la interpretación germaniana respecto de su disponibilidad, cooptación y manipulación-. Este horizonte demandaba, de acuerdo con Roldán, "concebir de manera más compleja la cultura de los sectores populares, la cual estaría abierta a múltiples influencias y atravesada por su imbricación en los procesos históricos" (2008, p. 216). En esta tarea, el trabajo etnográfico de Hugo Ratier (1971) resultó señero. Además, el contacto con el marxismo británico renovó el análisis de las identidades de las clases, sus prácticas y valores más allá de lo

\footnotetext{
${ }^{3}$ El cuestionario tenía 81 preguntas, divididas en siete módulos temáticos: 1) Vivienda y Hábitat; 2) Movilidades y Asignaciones Identitarias; 3) Vulneración de Derechos; 4) Alimentación y Nutrición; 5) Acceso a Bienes, Servicios y Ayudas de Otros; 6) Ingresos del Hogar; 7) Autopercepción de Clase.
} 
señalado por su inserción en la estructura productiva. Las limitaciones y determinaciones que acarreaba "clase obrera" derivó en su sustitución por el término "sectores populares" que, si bien no comportaría un sujeto histórico, señalaría un área de la sociedad en la que este puede llegar a constituirse como tal (Gutiérrez \& Romero, 2007, p. 41).

Hacia los ochenta, una de las principales vías para explorar el devenir de los sectores populares encontró en la escala barrial la posibilidad de "emprender la desestimación definitiva de la categoría de clase social y escribir una historia alternativa tanto a las tradicionales historias barriales como a las marxistas" (Roldán, 2008, p. 218). Estaba claro que la vida de los y las trabajadoras no se circunscribía únicamente al ámbito laboral, registrándose una diversidad de experiencias y subjetivaciones que impulsaron una agenda de investigación amplia acerca de sus identidades y formas de sociabilidad. Por una parte, la historiografía tomó cierta distancia de los estudios estructurales ligados a los modelos de acumulación económica (Torrado, 2010), "centrados fuertemente en el análisis de los mercados de trabajo y la pobreza" (Benza et al., 2016, p. 182). Esta agenda que marcó a la sociología argentina también encontró sus fugas (Benza et al., 2016). Los abordajes cualitativos propuestos por Jelin (1993; Jelin et al., 1987) en la transición hacia la democracia tuvieron un claro carácter innovador, tanto por su enfoque ligado a la construcción de ciudadanía como por las técnicas de investigación empleadas (Benza et al., 2016, p. 187). Además de hacer lugar a las autoadscripciones de clase, sus trabajos advirtieron las vinculaciones políticas de los sectores populares como una dimensión de la vida cotidiana.

Si en parte de la historiografía y de los estudios sociológicos cualitativos la noción de "sectores populares" se afianzó abarcando con el tiempo a un conjunto heterogéneo de grupos subordinados (trabajadores industriales, informales, desocupados, asistidos, pobladores de villas) surgidos de una combinación de criterios políticos y económicos (cf. Semán \& Ferraudi Curto, 2016, p. 142), no sucedió lo mismo cuando se trató de abordar "la obsesión por comprender el fenómeno peronista y explicar los mecanismos de adhesión inquebrantables de su base social (clase obrera)" (Roldán, 2008, p. 203). En trabajos ya clásicos como los de Murmis y Portantiero (1971) y de Torre (1990), "clase" resulta una piedra angular ineludible para discutir, entre otras cuestiones, las tesis de Germani. En el primero de los casos, esta categoría explica la alianza entre una elite populista y un movimiento obrero que se consolida y gana peso institucional, pero pierde su autonomía. En el segundo, permite advertir la configuración de una identidad política capaz de crear un sindicalismo de masas que integra y subordina a los 
trabajadores a los intereses de la elite gobernante. Entre otros, estos trabajos componen el "paradigma clásico" sobre las relaciones entre el movimiento obrero y el primer peronismo (1946-1955).

El agotamiento del paradigma clásico fue apuntado por Aldao (2018), quien observó los efectos obturadores de las construcciones binómicas que subyacen en estas lecturas (por ejemplo, autonomía/heteronomía del movimiento obrero ante el peronismo) y su correlato, la construcción de la idea de un "sindicalismo autónomo 'deseable' que se contrapone (y en el mismo gesto impugna) el desarrollo sindical durante el peronismo" (2018, p. 35). "El peronismo, en esta clave", se presenta como "el paradójico destino trágico del deber ser del movimiento obrero" que, a cambio de su inclusión como actor político, resigna "un rasgo inmanente de su subjetividad: su autonomía política" (Aldao, 2018, p. 34). Estas reflexiones resultan particularmente pertinentes aquí, pues se derivan del estudio del proceso de institucionalización y de la dinámica identitaria en la Unión Ferroviaria en el transcurso del primer peronismo.

Una perspectiva menos atravesada por los esquematismos en relación con la clase y su vínculo con la construcción de identificaciones políticas puede encontrarse en los trabajos de Adamovsky (2007, 2009, 2013). Su enfoque relacional, atento al modo en que las clases se construyen en el marco de relaciones de dominación/subordinación económica, política y cultural específicas, resulta esclarecedor. En principio, porque no da por sentada la existencia de una "clase" en virtud de la presencia de determinadas categorías ocupacionales, abordando aquello que tienen en común un conjunto de personas, pese a sus diferencias. Así, las "clases medias" indicarían una posición intermedia entre una superior y otra inferior (Adamovsky, 2013, p. 49), en tanto, las populares compartirían una experiencia común y fundamental de subalternidad respecto de las elites. Para hacer justicia a su perspectiva es necesario recorrer las articulaciones que delinearon las pertenencias a ambas clases, tema que abordaremos luego.

La historización de los criterios hegemónicos que delinearon la pertenencia a las clases medias en Argentina, particularmente los usos de esta categoría por parte de diversos actores del sistema político, constituye uno de los aportes destacados del trabajo de Adamovsky (2009). De acuerdo con su reconstrucción, esta comenzó a ser utilizada por la intelectualidad hacia la segunda década de siglo veinte como una suerte de dique de contención o frontera identitaria respecto de las identificaciones de los sectores populares con el comunismo y el anarquismo. Con sus matices, la izquierda argentina -el Partido Socialista y el Partido Comunistamostró signos de ambivalencia y de cierta dificultad para "situar" políticamente 
a la clase media. Entre las tendencias, quizás el Partido Socialista fue aquel que logró incorporarla, no sin recelo, en el discurso de su dirigencia y su política de alianzas (Adamovsky, 2008). En tanto, en la Unión Cívica Radical (UCR), fundada a fines del siglo diecinueve y concebida como un partido policlasista, asimilable al pueblo, la patria y la nación, las referencias a las clases medias eran bastante inusuales y denigratorias. Sus usos, como estrategia de equilibrio entre dos polos balanceados, se delineó hacia 1930 y su definición fue más política que social: estaba destinada a actualizar el discurso liberal clásico. Si bien la UCR contribuyó a inventar discursivamente a la clase media, no fue su expresión política desde su momento fundacional.

Según Adamovsky (2008), la adopción masiva de "clase media" se sitúa en los años del primer peronismo. Entonces, ser de clase media fue un modo de diferenciarse de la identificación como "trabajador". La clase media, por oposición, era blanca, antiperonista, porteña y europeizante. Desde esta perspectiva, la irrupción del peronismo como "hecho maldito" hirió esta imagen construida sobre la base de la invisibilización de las clases plebeyas que pretendían protagonizar la historia nacional. En este punto, señala Álvarez Leguizamón (2018), es posible que tal invisibilización tuviera que ver más con su condición de clase obrera que con su existencia subalterna. En cualquier caso, la "cuestión plebeya" del peronismo surge como una frontera de clase que se arraigó en la historia política y social argentina.

Tras la autodenominada "Revolución Libertadora" (1955) las izquierdas volvieron a colocar al trabajador en el centro del desarrollo, en tanto el peronismo, tras el fracaso de movilizar a los sectores medios, se inclinó hacia su desprecio (Adamovsky, 2007). De hecho, el golpe de 1955 fue leído como un movimiento de clases medias. No fue mucho el tiempo que pasó para advertir este error que derivó en la automortificación de la pequeña burguesía incorporada al peronismo desde los sesenta (Altamirano, 1997). Aun cuando fueron parte de sus bases electorales en distintos periodos, el divorcio del peronismo respecto de las clases medias fue materia de debates y controversias recurrentes.

De esta breve síntesis se deriva una de las principales conclusiones de Adamovsky (2009, p. 106): en distintos momentos históricos, "clase media" tuvo un sentido "contrainsurgente", estableció diferencias y quebró solidaridades. Esto impactó en su representación política: pese a su arraigo en el lenguaje, las clases medias carecen de organizaciones que defiendan sus intereses, como sucede en otros países. Adamovsky (2009) se pregunta a qué se debe esta la ausencia. Una primera hipótesis es que el movimiento obrero siempre se mostró predispuesto 
a amparar a los no-obreros. Habría así un desacople entre la identidad de un individuo en su fuero interno y la que profesaría colectivamente en el espacio público. Vale preguntarse si, en lo reciente, esta disonancia no excede a las experiencias políticas de las tradicionales clases medias. En este punto resulta crucial recuperar los aportes de la sociología de los noventa y sus indagaciones respecto de la "experiencia masiva de empobrecimiento" para el país (Minujín \& López, 1994, p. 92).

En este periodo de segmentación, heterogeneización y polarización social, el aumento de la desigualdad de ingresos determinó quienes resultaron los "ganadores" y los "perdedores" de la reconversión capitalista neoliberal (González Bombal \& Svampa, 2001; Minujín \& Kessler, 1995; Svampa, 2005). La atención sociológica se dirigió entonces a analizar las redes y los mecanismos sociales activados por las familias para mitigar o sortear con mayor o menor éxito los procesos de movilidad descendente que originaban a los "nuevos pobres": aquellos sectores medios de la población que, por el deterioro de sus ingresos, se encontraban ante la imposibilidad de acceder a los bienes y servicios básicos necesarios (Minujín \& López, 1994, p. 94). Su constitución, producto de una pobreza adquirida, no heredada, dio lugar a su caracterización como un "estrato híbrido", cercano a las clases medias en sus aspectos culturales (familias pequeñas, nivel educativo), pero también a los pobres estructurales en términos de niveles de ingreso, desempleo y precariedad laboral (Kessler \& Di Virgilio, 2008). La literatura apuntó su coacción al cambio, el desorden de las prácticas de consumo, su distribución heterogénea y no concentrada en los intersticios de las tramas urbanas, subrayando un modo específico de explicar su declive: como efecto de la desaparición de la clase media y no de una desafiliación individual que los situaba en la pobreza.

En la reabsorción de los efectos de la restructuración neoliberal y la condición subalterna, Míguez y Semán (2006) apuntaron tres categorías que permitirían caracterizar el mundo popular para principios del siglo XXI: fuerza, jerarquía y reciprocidad. La primera -fuerza- alude a una potencia física y moral asociadas a un sistema de valores. La segunda -jerarquía- abre una perspectiva desde la cual se puede observar, por ejemplo, la dinámica familiar que oscila entre el patriarcado y el conservadurismo y las tentativas de igualación y horizontalidad. Esta señala un modo de advertir la tercera categoría -reciprocidad-, concretamente las relaciones políticas y las mediaciones que suponen. En el mundo popular, apuntan los autores, "las relaciones no son nunca entre iguales abstractos como piensa el derecho, sino entre personas singulares que merecen un trato según el tipo" (Míguez \& Semán, 2006, p. 27). Esto resulta crucial para comprender 
la problematización del "lazo político" desde la crítica a las lecturas instrumentales del "clientelismo" (Vommaro \& Quirós, 2011).

Si bien en la literatura antropológica de las últimas décadas el estudio de la "política popular" no fue acompañado por un debate explícito sobre la clase, tal como se registra en la historiografía, ni por "un debate estructurado en torno a la composición y pesos relativos de los diferentes sectores, como en el caso de los estudios sociológicos cuantitativos" (Benza et al., 2018, p. 189), sus contribuciones son destacables (Visacovsky, 2008). Los análisis etnográficos de los años noventa captaron la revitalización del territorio y el surgimiento de una cantidad de organizaciones y redes orientadas a la gestión de recursos estatales que buscaron atender la pobreza (Auyero, 2001; Ferraudi Curto, 2006; Masson, 2004; Merklen, 2005; Quirós, 2006). Estas investigaciones revisten gran importancia en tanto que, además de introducir la perspectiva de género, recuperaron y actualizaron de un modo crítico las preguntas por el peronismo introducidas en los sesenta.

Los trabajos arriba mencionados resultan indisociables de la disrupción que supuso la crisis de 2001. A partir de entonces comenzó a conceptualizarse la existencia de un "proletariado plebeyo", excluido del mundo de los trabajadores sindicalizados (Svampa, 2009); también las (auto)denominadas clases medias fueron pensadas a partir de las diversas lógicas relacionales de reconocimiento e identificación que operan en la vida cotidiana (Visacovsky \& Garguin, 2009). Estos estudios resultan claves para establecer la distinción entre variables objetivas y autopercepción de clase, en tanto abordaron sus economías y moralidades.

En lo reciente, los sectores populares presentan otro cuadro en lo relativo a las posiciones estructurales que habían ocupado en los estudios precedentes (Semán \& Ferraudi Curto, 2016). La recuperación general del empleo y de las remuneraciones, también la implementación de transferencias monetarias modificó la realidad de los hogares, aunque sin trastocar los niveles de inequidad previos a la crisis de 2001. En este punto, "la situación de los sectores populares se inscribe en una curva en la que las mejoras del presente resultan parciales respecto de un pasado cada vez más lejano" (Semán \& Ferraudi Curto, 2016, p. 145).

Los últimos años añaden otro dato que permite advertir la particularidad de la coyuntura: a diferencia de periodos anteriores, la pobreza no se registra exclusivamente entre quienes son receptores de planes y políticas sociales redistributivas, también abarca a empleados cuyos ingresos no llegan a sobrepasar la línea de flotación (Semán \& Ferraudi Curto, 2016). El heterogéneo mundo popular se compone entonces de: i) generaciones empobrecidas que perdieron inserciones laborales y que desde allí consolidaron trayectorias de movilidad inter- 
generacional; ii) personas que partieron de niveles de pobreza casi naturalizada de la que no pudieron transcender; iii) sujetos que dejaron atrás estas circunstancias y jefes de hogar para quienes el trabajo apenas solventa el empobrecimiento (Semán \& Ferraudi Curto, 2016, p. 151).

En términos políticos, la sedimentación de los procesos de organización territorial para la gestión de distintas políticas públicas se diversificó (Semán \& Ferraudi Curto, 2016, p. 156). Hacia 2009, emergió una nueva convergencia entre el "proletariado plebeyo" (Svampa, 2009) y el Estado, con una revitalización sindical que incluía como novedad la organización predominante de ramas del trabajo precario e informal. De ahí que la posición social en el mundo popular, su amplia heterogeneidad, pueda ser leída como producto articulado de sus trayectorias ocupacionales y de los lazos políticos creados por diversos activismos y por el Estado (Semán \& Ferraudi Curto, 2016, p. 162). Esto colabora a la hora de explicar el proceso electoral que en 2015 colocó a Mauricio Macri en la presidencia. Varias apuestas explicativas guían lo que aún es una reflexión coral en curso. Se pone de relieve el bienestar precario otorgado a los sectores informales y una fuerte crisis de la imagen pública del kirchnerismo (Vommaro \& Gené, 2017) que logró transformarse en una expresión política y electoral arraigada en "un proceso de reconocimiento de deseos y aspiraciones que anuda una identidad colectiva" (Bonazzi et al., 2017). Pero vayamos ahora a Barrio Operario para explorar cómo, en diversos momentos, autoidentificaciones de clase e identificaciones políticas se alimentaron, explicaron y agenciaron.

\section{UNA CLASE PARA UN BARRIO (1948-1955)}

Barrio Operario comenzó a formarse a fines de los cuarenta, cuando el gobierno de Juan Domingo Perón tomaba posesión de las líneas ferroviarias de capitales británicos y franceses y creaba el "Ferrocarril Nacional General Belgrano" (1948). Su origen está íntimamente asociado a este proceso de estatización que fuera parte de la "estrategia justicialista" de desarrollo (Torrado, 2010), caracterizada por una activa política distribucionista e incluyente, por la inversión pública directa en industrias y servicios que permitió la coexistencia de flujos de movilidad estructural ascendente y descendente (Kessler, 2016). En este esquema, el tren era una pieza fundamental que permitía imaginar la Nueva Argentina; a "cientos de miles de empleados y obreros dotados de una sólida tradición sindical encargados de trasladar, con la precisión de un reloj suizo, la mayoría de las mercancías y personas a lo largo y ancho del país" (Aldao, 2018, p. 139). 
Hacia 1950 eso reflejaba el sindicato que los nucleaba, la Unión Ferroviaria (UF), aunque unos años antes la situación era bien distinta: para 1943 la actividad acumulaba más de una década de crisis que la futura gestión peronista buscó desandar.

Barrio Operario, entonces, no fue hijo de la pujanza ni de la capacidad de ejecutar las políticas que en materia social la rama desplegó en las décadas anteriores, cuando gremios como La Fraternidad y la Federación Obrera Ferrocarrilera disputaban espacios, obras y actividades a las empresas en un intento de legitimar una conciencia de clase por sobre la acción social empresarial. Más bien, fue hijo de la crisis por acumulación de este paradigma. Las primeras familias llegaron desde distintas provincias, particularmente desde Catamarca, Tucumán, Jujuy y Santiago del Estero, aquellas que estaban unidas a la Capital Federal por "las vías del Belgrano" y las trayectorias laborales de los varones. Estos y sus familias llegaron a Buenos Aires en virtud de los traslados dispuestos por la empresa, acuciados por la merma del poder adquisitivo de sus salarios, cuando la nacionalización ya era un hecho y estaba cargada de esperanzas entre las bases de un gremio que creció exponencialmente en la década precedente. ${ }^{4}$ Por entonces la UF se había vuelto una pieza clave en la unificación de la Confederación General del Trabajo (CGT) -cuya primera secretaría general ocupó un ferroviario- y parte crucial del proyecto peronista. La "familia ferroviaria" había participado protagónicamente de la formación del Partido Laborista (gestionando la tensión entre el principio de prescindencia política del sindicalismo y la participación política de los agentes sindicales), ocupaba posiciones en la nueva burocracia estatal y en niveles locales, provinciales y nacionales del gobierno (Aldao, 2018, p. 95).

Desde que Perón asumió en 1943 la Secretaría de Trabajo y Previsión (STP) hasta su derrocamiento (1955) la UF fue un sindicato crecientemente "defensor de las políticas del peronismo" (Aldao, 2018, p. 12). Pero no se trató de un juego de suma cero, las reivindicaciones que obtuvieron los ferroviarios durante los primeros meses de la STP tuvieron por contrapartida el apoyo que el gremio dio a la cartera. Esto fue parte de la consolidación del proceso de identificación de los ferroviarios con el naciente peronismo que tuvo su ápice en 1950, cuando la UF adoptó en su estatuto la doctrina peronista.

Quienes fundaron Barrio Operario no integraban el proletariado rural llegado a la ciudad, aquel que suele ser considerado para caracterizar la significativa movilidad de corta distancia en el periodo, sino que eran parte de la industria

\footnotetext{
${ }^{4}$ Para septiembre de 1945, la UF contaba (según cálculos del sindicato) con más de 100.000 asociados y 264 seccionales, más de 30.000 afiliados más que en 1941 (Aldao, 2018).
} 
ferroviaria en sus provincias de origen. No obstante, parafraseando a Ratier (1971), componían la marcha de "la pluma negada" hacia el corazón de la "Argentina Blanca", aquella formación afectiva y geográfica que no es reducible a ideologías o discursos (Gordillo, 2020). En su conjunto, integraban los masivos flujos migratorios internos que, frenada la migración de ultramar, sustituyó este aporte de fuerza de trabajo, aunque sin correr el mismo destino (Trovero, 2016).

Los varones mayores de las familias eran, en su mayoría, trabajadores ferroviarios calificados (mecánicos, carpinteros, capataces, jefes de estación, guardabarreras) y no calificados (zanjistas, cocineros, remolcadores, foguistas, cambistas). Las mujeres se desempeñaban -según se autodenominaban entonces y lo hacen ahora- como "amas de casa". Algunas completaban los ingresos familiares trabajando como costureras o tejedoras. Cada vagón en desuso, de doce metros de largo y dos metros y medio de ancho, montado sobre durmientes de quebracho, constituyó una unidad habitacional a la que Ferrocarriles Argentinos proveyó de agua potable, en tanto la energía eléctrica fue gestionada a partir de la conformación de una cooperativa vecinal. Así, contaban los vecinos más antiguos, "se sobrevivía [...] un vagón, otro vagón, otro vagón, sí, en una fila de vagones" en la que Héctor vivió por 13 años (Héctor, comunicación personal, 10 de octubre de 2019). Estaban ubicados, recordaba Mariano, en medio de "un desastre de cucarachas, ratas, víboras, lo que quieras. Bajaba el agua de una fábrica y se inundaba, la gente abría la puerta para que pase el agua" (Mariano, comunicación personal, 21 de octubre de 2019). "Era la miseria absoluta, no había nada de dignidad, se vivía como animales", completaba Milton (comunicación personal, 8 de septiembre de 2020). Los tres, antes que jóvenes o hijos de trabajadores en el sentido reivindicativo que el primer peronismo otorgaba al término, se describían como "pobres".

Si la identificación peronista de sus habitantes precedió al barrio, no fue igual para la autoadscripción de clase que, a priori, parecía corresponderle. Para nombrarse "trabajador", "obrero", no resultaba suficiente la condición de asalariado, se requería un piso mínimo de dignidad que implicara cruzar el umbral hacia la antropoformización, cuya corroboración era primordialmente material: se trataba de disponer de una casa propia, piedra angular y aspiracional de las identificaciones asociadas a las clases medias. Vimos que la identidad de "clase media" surgió en la Argentina como reacción contra el empoderamiento de la clase trabajadora durante el primer peronismo (Adamovsky, 2009). Estas, influenciadas por el racismo de las clases dominantes, se sentían blancas en oposición a la expansión espacial y política de los sectores subalternos racializados que 
denominaban "cabecitas negras". Diferentes espacios políticos compartieron un imaginario que yuxtapuso la etiqueta de clase ("obreros", "descamisados") a la racial ("cabecitas negras") y a la política ("peronistas") (Grimson, 2019, pp. 61-65). Esto marcó la polarización entre las posiciones hegemónicas que, pese a su compleja heterogeneidad, estableció una dicotomía simbólica de larga duración y renovado aliento: "peronistas y antiperonistas". Difícilmente podamos entonces comprender las dinámicas históricas de este binomio y las seguidas por las diferenciaciones de clase sin considerar el papel constitutivo del racismo en su conformación (Grimson, 2019).

En el caso de Barrio Operario, la identificación peronista se completó con la transformación de la autopercepción de clase, a partir de los indicios de una movilidad social ascendente que incorporaba a las y los vecinos a la concreción de la justicia social. Esta movilidad abrió las puertas a la posibilidad de enunciarse "trabajador" para habitar así una clase obrera que recogía los ideales atribuidos a las clases medias. A poco de iniciarse el primer mandato presidencial de Juan Domingo Perón (1946-1952), comenzaron a construirse los chalets que aun hoy se destacan en Barrio Operario. Su construcción bajo la impronta pragmática de la máxima "mejor que decir es hacer y mejor que prometer es realizar", ligó autoadscripción de clase e identificación política de un modo que no volvería a repetirse. Varias eran las razones. En principio, familias como las de Héctor, Milton y Mariano fueron parte de quienes no titubearon el 17 de octubre de 1945. Mientras la dirigencia de la UF intentaba una estrategia dilatoria, pedía "pensar diez veces antes de tomar una resolución" como la convocatoria a la movilización obrera para pedir la libertad de Perón (Torre, 1990, p. 131) en el norte, los trabajadores del Belgrano ya habían abandonado sus puestos para emprender una marcha que se inició en Tucumán y se expandió a Salta y Jujuy. Posiblemente se haya tratado de una de las primeras ocasiones en que la lealtad no emanó de la disciplina sindical, sino lo contrario. Quizás por ello también, tiempo después, Perón se refería a los ferroviarios como "los juglares que cantaron, a lo largo de toda la tierra argentina, las esperanzas y las ilusiones de las primeras horas justicialistas" (Aldao, 2018, p. 61).

Sin embargo, no se trataba sólo de honrar aquella lealtad fundacional gestada cuando las familias del nuevo Barrio Operario aún vivían en el norte del país. Dicha lealtad también fue refrendada en el transcurso de las emblemáticas huelgas que comenzaron en noviembre de 1950 y se extendieron hasta enero de 1951. Entonces, el Belgrano fue el único ramal que nunca detuvo su marcha (Contreras, 2009). Un año después, la adhesión reclamada por Perón -“emplear a los pero- 
nistas y desplazar a los que no sean peronistas"- cobró entidad: Carlos Ernesto Rosales, dirigente del departamento de tráfico del Belgrano, fue electo presidente de la UF. Quizás la suma de todos estos posicionamientos y correlatos es lo que permite a Celia afirmar que, ayer y hoy, Barrio Operario está poblado "por auténticos y leales peronistas" (comunicación personal, 23 de septiembre de 2020). Como una suerte de frontera interna y antagónica, su definición identifica "falsos peronistas" o peronistas disfrazados de tales, aquellos que cobrarán peso y sanción a partir de 1955 .

Evocar la transformación parcial de aquel pastizal poblado de vagones en tres manzanas de viviendas es dar cuenta de las formas en que se retroalimentó la organización vecinal, el comienzo de lo que sería un largo diálogo con diferentes áreas de la administración pública y la identificación peronista. Estos tres vértices permiten narrar el ideal de una "comunidad organizada" a la que "todo el barrio se sumó", en la que "todos los compañeros tenían una tarea". Por ello, frases como "está casa la hizo Perón" están lejos de desagenciar a quienes confrontaron a la dirección de la empresa, recorrieron ministerios y oficinas públicas, hicieron trámites y presentaron el resultado de censos e informes que elaboraban y sistematizaban las necesidades de las familias. Es decir, a quienes, como señaló Héctor, hicieron todo lo necesario para que, primero, otros "vinieran a ver", "verificaran" y, luego, el General diga "acá podemos hacer tres barrios".

Si la consumación del proyecto de viviendas puede ser atribuida a un Estado receptivo y sensible ante las necesidades de las personas, su imaginación incluso, su conquista- tiene por protagonistas a los vecinos, particularmente a los varones sindicalizados. La escenificación de las reuniones para debatir sobre los planos narrada por Milton da cuenta de esta distinción nada menor:

¿Quién [diseñó] estas casas? Fulano de tal... No, ¡díganle que no! Esta casa tiene que tener por lo menos cinco metros de jardín después de la vereda y la calle. Y de fondo $10 \mathrm{o}$ 20 metros, porque si la gente quiere hacer o plantar verduras, ahí en el fondo tiene para plantar [...]. Y, ¡ahí las tenés! Fondos de 30 metros, ¡Mirá qué chalet! (Milton, comunicación personal, 12 de noviembre de 2019)

Lo mismo sucede con el registro del proceso seguido para la adjudicación de los chalets que cristaliza la movilidad social y la identificación peronista sin obviar que, parte de ella, incluía la clase en tanto confrontación con la patronal:

Terminaron las casas, todas las casas, entonces nos llaman los capos del ferrocarril: "¿Qué pasa con las viviendas?”. "Ah, dice el General que ya están terminadas”. “Cuándo la entregan?". "Ya estamos por entregarlas, es que estamos haciendo una lista de los que van a ir allá o allá...”. [...] Me dan la lista y “¡no, esto no es así!”, porque en la lista habían puesto a los jefes... “ ¿Sabe que van a hacer ustedes?, tal día llamen a la gente y la citan en un lugar y traigan un bolillero, y va sacando cada uno, una bolilla. El número de 
la bolilla es el número de la casa... ¡Eso es obra social, eso es pueblo! ¡Perón era pueblo! [...]. Y eso no me lo olvido nunca...y bueno, fueron sacando [...]. Sacó número ella [su esposa], el número 22, la casa [que] le dieron [fue] la 22. Ellos [la familia de su esposa] vivían en un pasaje que no valía nada, imagínate para la gente que estaba en carpa, con barro y todo [...]. Lloraban, lloraban. (Milton, comunicación personal, 12 de noviembre de 2019)

Prontamente, el sueño de tres barrios obreros que agenciaron una identificación política preexistente en lo que era la periferia de San Isidro quedó reducido a tres manzanas de amplios chalets de ladrillo a la vista y techos de tejas. Las viviendas que llegaron a construirse materializan y patrimonializan la sutura entre la autoidentificación de clase y la identificación política que venimos señalando. En suma, constituyen la evidencia material que pacta el lazo político, la justicia social y la lealtad para con quienes transformaron las condiciones de vida de sus primeros habitantes.

El golpe de Estado de 1955 que inició la autodenominada Revolución Libertadora marcó a fuego el barrio. Un año después, el fusilamiento de dos de sus vecinos -Nicolás Carranza y Francisco Garibotti- no fue la regla represiva local, sino la excepción que confirmó el silencio y el repliegue masivo de lo que hasta entonces era una intensa vida comunitaria en pos de su urbanización. No es este el lugar para volver sobre la "Operación Masacre" en los basurales de José León Suárez, hito de los 17 años que duró la "resistencia peronista", solo se trata de apuntar algunas aristas de su subjetivación local. En Barrio Operario, este masivo encuentro con la represión ilegal condensa diversas versiones e interpretaciones que suelen expresarse como narraciones escenificadas e inacabadas. En estas, se identifican actores, se exponen valoraciones y se ofrecen reflexiones y representaciones sobre el pasado, el presente y el futuro. Vale detenerse en algunas de las que registramos.

Desde comienzos de los setenta, Berta y Delia, hijas de Carranza y Garibotti, respectivamente, que aún viven en el barrio, fueron entrevistadas para los más diversos proyectos intelectuales, académicos y artísticos: desde libros y tesis académicas hasta películas documentales y de ficción. En estas circunstancias, uno de los primeros en entrevistarlas posiblemente haya sido Rodolfo Walsh, cuando realizaba la investigación que derivaría en "Operación Masacre" (1972). Sus testimonios cobraron legitimidad y autoridad a la hora de establecer un modo de construir una memoria barrial.

En el relato de Delia, cuatro tropos se reiteran casi sin excepción: i) la condición de prófugo de su padre, quien no portaba armas; ii) la angustia de su madre y el pedido desesperado para que este se entregue; iii) la negativa de Garibotti y la voluntad de tranquilizar a su mujer; iv) las gestiones conjuntas de 
ambas familias para poder velar y enterrar los cuerpos de los dos vecinos. Pero lo que aquí se vuelve relevante es lo que sigue a la noche del 9 de junio de 1956. Las narraciones de ambas se entrelazan en el curso de las tragedias familiares: las vidas sacrificadas y colmadas de necesidades de sus madres, dos jóvenes viudas a cargo de seis hijas e hijos cada una, que hicieron lo imposible para sacarlos adelante; los hermanos varones que eran detenidos en virtud de sus apellidos cada dos por tres, "aunque fueran a bailar"; y el registro implacable del silencio barrial. A comienzos de los 2000, Delia decía:

Mi mamá nunca más quiso que se tocara el tema. Y eso fue hasta que nos hicimos grandes... por miedo. Nosotros nos criamos así, estábamos enmudecidos, con temor, porque no podíamos hablar con nadie. Cuando aquella noche estábamos desesperados buscando a nuestros padres, nadie del barrio salió a ayudarnos. Todos tenían miedo de comprometerse. Era una sociedad que nos marginaba. (Delia Garibotti, en Garulli et al., 2000, p. 106)

Hoy, otras narrativas elaboran y responden generacionalmente a las palabras de Delia. Entre quienes, como Héctor, fueron vecinos y contemporáneos de ambos militantes prima la descripción de las circunstancias en que fueron apresados. En ellas, el barrio no permanece ajeno:

Eso fue una denuncia de un vecino que andaba trabajando con la policía, y eso alertó a la gente. Fueron en un colectivo 130, de los viejos de antes, a Munro, que es donde los secuestraron, y lo llevaron al basural de León Suárez. Ahí lo acribillaron a balazos [...]. Los conocí a los dos. Carranza, que era camarero en ese entonces, andaba en el Belgrano. (Héctor, comunicación personal, 10 de octubre de 2019)

Entre quienes, como Mariano, Ricardo y Camila, nacieron años después de los fusilamientos de Carranza y Garibotti, pesa más la ponderación de las identificaciones políticas y sus derivas. Estas se enlazan con la experiencia barrial del terrorismo de Estado en el segundo lustro de los setenta, conformando un continuum que tensiona la identificación vecinal y la construcción de la responsabilidad -incluso en términos de agencia-que cabría a los militantes por fuera de los alcances de la "pura víctima". Aunque "peronistas de izquierda" los tres, sus descripciones no decantan de igual modo:

Acá [en el barrio] hay mucha gente que militó, el mundo dice que pensaban diferentes, que eran subversivos, pero yo estaba de acuerdo en un montón de cosas, ¿no? A Garibotti y Carranza los llevan cuando no se podía reivindicar el peronismo, y bueno, fueron a reivindicar al peronismo y terminaron en [José León] Suarez. (Mariano, comunicación personal, 21 de octubre de 2019)

Ricardo: Fueron fusilados en un parque que ahora es centro deportivo, en esa época era un basural. Los fueron corriendo, desde acá escapaban... Yo sé la historia por toda la gente del barrio vieja ¿Viste?... La gente vieja nos contaba la historia, acá los seguían a ellos y ya los tenían cerca porque los seguían de parte del gobierno, los militares, y bueno se escapaban y llegaron a esa parte, corrieron 
por el basural y los agarraron y al paredón y los mataron... Eran ferroviarios ellos dos...

Camila: A lo que él contó, ahora te cuento el por qué... A ver, éramos muy discriminados acá en el barrio porque se hablaba en la época de los militares, que en este barrio había muchos subversivos. Entonces la gente no nos podía ni ver, pero ¿Qué culpa teníamos nosotros que no teníamos nada que ver?

Ricardo: Claro, nos metían a todos en la misma bolsa. (Ricardo y Camila, comunicación personal, 12 de noviembre de 2019)

La imagen de un barrio tomado por el miedo, "marcado" por este hecho, contrasta con la descripción de "la época en la que el peronismo era una fiesta" (Delia Garibotti, en Garulli et al 2000, p. 106), señalando simultáneamente una desafiliación. Hasta aquí la identificación "peronista" se completó en el reconocimiento simbólico y material de la condición de "trabajador" delineada a partir de los criterios aspiracionales asociados con las clases medias. Lo que sigue será un largo y paulatino proceso de movilidad descendente que transformará la lógica de la relación entre identificación política y autoadscripción de clase. A lo largo de las próximas décadas el barrio cambiará su paisaje: en su desborde devendrá "villa" y las identificaciones políticas ganarán matices y heterogeneidad.

\section{(DES)BORDES (1960-1990)}

Según Torrado, a la "estrategia desarrollista" (1958-1972), marcadamente concentradora y excluyente, siguió la "aperturista" (1976-2002), caracterizada por procesos de desindustrialización, concentración y expulsión (Torrado, 2010). Este segundo periodo permite reconocer dos etapas: la primera, a mediados de los setenta, señala el comienzo de la transición hacia un modelo neoliberal caracterizado por la valorización financiera, las privatizaciones y la apertura externa. La segunda, en los noventa, marcó su consolidación. El escenario de desindustrialización y desocupación de mano de obra calificada alcanzó los mayores niveles durante la crisis de 1998-2002, señalando la fase final de la desarticulación productiva y su entramado social.

Hacia 1960 el país evidenciaba un carácter comparativamente equitativo en cuanto a la distribución del ingreso, se caracterizaba y distinguía por el peso y el tamaño de las clases medias, por una clase trabajadora consolidada con niveles de empleo y de salarios comparativamente altos, y con un amplio acceso a los derechos sociales (Kessler, 2016). Según Dalle, la representación gráfica de la estructura social para el periodo 1960-1970 indicaría "una amplia zona media constituida por las clases medias y una clase trabajadora consolidada, y una forma más afinada en los extremos" (Dalle, 2016, p. 55). Incluso, una década después, 
la Argentina de comienzos de los ochenta "no conocía todavía ni altos índices de desocupación, ni el empobrecimiento pronunciado de sus clases medias, ni el desmantelamiento de su modesto estado de bienestar (que garantizaba aceptables niveles de educación y salud para la mayoría de la población)" (Carassai, 2013, p. 18). No resulta sencillo situar homogéneamente en este cuadro a los y las vecinas de Barrio Operario.

Durante la presidencia de Arturo Frondizi (1958-1962) se sentaron las bases de lo que sería, salvo algunos momentos puntuales de recuperación, el largo declive del sistema ferroviario. La pérdida de miles de puestos de trabajo, el descenso del transporte de cargas y pasajeros, el cierre de ramales y la tercerización de algunas tareas fueron "transformando al gremio en un comunicador de derrotas crónico" (Damin \& Aldao, 2015, p. 35). Este, además, debió afrontar una intensa campaña de desprestigio que enfatizaba el déficit ferroviario y la impericia de su gestión estatal. La crisis golpeó a los trabajadores del riel, cuyo capital político quedó fuertemente dañado tras la contundente huelga de 1962, pero también involucró al propio gobierno de Frondizi. Este, fundado en un pacto con el peronismo, vio tambalear su escasa legitimidad al tiempo que los ferroviarios se trasformaron en las principales víctimas de sus políticas antiobreristas (Damin \& Aldao, 2015, p. 36).

Tras un breve periodo de recomposición del sector a inicios de los setenta, la dictadura iniciada en 1976 continuó con una política de levantamientos de recorridos y reducción de personal. ${ }^{5}$ Esta retracción trastocó completamente el panorama sindical y la valoración del sindicato por parte de sus afiliados. Veamos cómo anclaron en Barrio Operario estos procesos estructurales ligados al modelo de acumulación que comenzaba a imponerse en el país.

El primer registro de estas transformaciones remite al paisaje. Barrio Operario "se agrandó" por su propio crecimiento vegetativo, con la construcción de nuevas unidades habitacionales en los terrenos originales, pero también por el arribo de nuevas familias que fueron estableciéndose precariamente en sus márgenes. Aunque hoy para cualquier visitante tal desborde sea imperceptible, las y los vecinos de mayor antigüedad se empeñan en marcar los límites que establecerían dónde comienza y termina Barrio Operario respecto de lo que consideran "nuevos" -otros- barrios. Estos, que avanzaron desordenadamente sobre los terrenos del ferrocarril, trajeron consigo un actor hasta entonces ausente. Según

\footnotetext{
${ }^{5}$ En 4 años, entre 1976 y 1980, se perdieron más de 5500 kilómetros de vías y casi 60000 puestos de trabajo (Martínez, 2007, p. 285).
} 
Camila, los lotes despoblados "fueron repartidos por punteros políticos [...]. Teóricamente habían formado una cooperativa para [...] las personas del ferrocarril y sus hijos, pero muchos de los hijos quedaron sin terreno y se vendieron a gente que venía de otra parte" (Camila, comunicación personal, 12 de noviembre de 2019). Por esta razón, el barrio ya no es considerado "netamente ferroviario, hay algunos ferroviarios, con mucha gente que venía de otra parte". Esta nueva situación, siguiendo su relato, cambió "la clase de gente" y "el ambiente" (Camila, comunicación personal, 12 de noviembre de 2019).

La transformación del barrio que compartía Camila y otros entrevistados podría leerse rápidamente en la clave "establecidos" y "outsiders" (Elias $\&$ Scotson, 1994). Sin embargo, nos interesa porque refleja la autoidentificación de clase ligada a la experiencia de una movilidad social ascendente en la primera y segunda generación del barrio en los sesenta y setenta y, además, por la oclusión política que la acompaña. Si el barrio devino "villa" no fue en virtud del empobrecimiento de las familias ferroviarias, sino a raíz de quienes llegaron allí. Regresemos a Héctor para explicarlo.

En 1960, Héctor era peón en el Ramal Belgrano, cortaba el pasto, cavaba zanjas, era la tercera y última generación de ferroviarios de su familia. Con 44 años de servicio, a comienzos de los 2000, se jubiló como capataz de primera en la sección de remolcado. Cuarenta años antes se casó con la vecina que vivía en el vagón contiguo al que habitaba con su familia, aquella con la que más le gustaba jugar de niños. En 1961, aun cuando podría haber pedido la excepción correspondiente por su estado civil, decidió hacer el Servicio Militar. Además de aprender a "respetar" y "coser un botón", su sueldo de cadete sumó a la economía doméstica y le permitió terminar de arreglar la casa de material a la que pudo acceder poco tiempo antes, con la ayuda de su suegro, también trabajador ferroviario. Dejar el "vagón", dar estudio a su hijo, hoy oficial del Ejército, e hijas, ambas empleadas públicas, es narrado como sigue: Mis hijos todos se han educado [...]. Vivíamos en un vagón, ¿eh? En un vagón vivíamos
nosotros [...]. Gracias a la virgen, estoy agradecido de vivir en un vagón [...]. Con el
poco sueldo que tenía, con ella [su esposa], con toda la voluntad de ella, preocupados por
el estudio, por comprar los libros, todo. Nos costaba, pero... [Hay] gente que se arre-
piente, "menos mal que salí de esa mugre" [...]. Tenés que estar agradecido de criar a tu
hijo en un vagón [...]. Yo, al contrario, estoy orgulloso de haber vivido en un vagón, ahí
crie a mi hijo, todos vivieron allí. (Héctor, comunicación personal, 10 de octubre de 2019)
La movilidad intra- e intergeneracional experimentada por las familias del
barrio vinculadas al ferrocarril es objeto de reivindicación: de una reivindicación
a falta de reconocimiento que, en el mismo gesto, señala su agotamiento. Héctor 
y su mujer no fueron la única pareja que avizoró para sus hijos e hijas un futuro lejos del gremio del riel. Ellos, al igual que Camila y Ricardo, siguieron otro camino.

Ricardo vivió toda su vida en Barrio Operario, es hijo y nieto de trabajadores del ferrocarril. Camila, por su parte, llegó al barrio procedente de Jujuy cuando tenía 12 años y a su padre, también ferroviario, lo trasladaron a la seccional de Boulogne. Ambos crecieron en los chalets y, luego de casarse, en los noventa, pudieron comprar uno. Cuando los entrevistamos, de la puerta de su casa colgaba la bandera wiphala, en señal de apoyo a Evo Morales que acababa de ser destituido de la presidencia de Bolivia.

En los setenta, Camila comenzó su educación formal en colegio católico de Martínez donde completó el nivel primario y secundario. Luego realizó el curso de martillera, pero nunca ejerció: después de casarse se dedicó a la peluquería que montó en el barrio. Ricardo, su marido, también completó los estudios secundarios. Al finalizarlos, su padre no quiso presentarlo ante la empresa ferroviaria: "mi papá no quería, me decía 'búscate otra cosa porque en el ferrocarril vas a estar toda la vida igual', el me aconsejaba que no entre ahí" (Ricardo, comunicación personal, 12 de noviembre de 2019). Luego de alternar diversos empleos, ingresó al CEAMSE. A diferencia de sus padres ferroviarios, Camila y Ricardo no pasaron una infancia de privaciones, pero no por ello la movilidad ascendente que comportaban sus respectivas trayectorias familiares y personales aparecían reconocidas como tales; "la gente de afuera del barrio te tenía como que fueras de otra clase", afirmaba y ejemplificaba Camila:

Yo tengo una historia. Tendría 13 años [en 1979] e iba a un colegio que en ese tiempo era de monjas. Tenía una amiga en ese tiempo que vivía a una cuadra y media [de su casa], entonces combinamos que ella iría a mi casa y después yo iría a la casa de ella. Cuando su tía, que era donde ella vivía se entera de donde vivía yo, no la dejó...Le pidió que ni me hablara. (Camila, comunicación personal, 12 de noviembre de 2019)

Ricardo completaba este desacople entre las representaciones del barrio, las trayectorias y autopercepciones de clase de sus habitantes. Aun cuando eran años en los que "se podía progresar" y la "gente ferroviaria tenía cosas, auto, vacaciones en Mar del Plata", como contaba Mara, vecina y par generacional de ambos (comunicación personal, 10 de septiembre de 2020):

Si ibas a buscar trabajo y decías que vivías en el barrio no te daban trabajo [...]. Cuando era chico, viste que ponían un cartelito si necesitaban un empleado, entonces yo iba con el cartelito y les decía "yo vengo por el cartel” y decían "bueno, bárbaro ¿Cómo te llamas?”, ["Ricardo”], “Dónde vivís?”. "En Barrio [Operario]”. “Ah, no”, decían [...]. Entonces teníamos que mentir, muchos de los que conseguíamos trabajo teníamos que mentir en la dirección. (Ricardo, comunicación personal, 12 de noviembre de 2019) 
¿Qué había sucedido? ¿Cómo explican o a qué atribuyen los vecinos esta disonancia? No hay una única respuesta posible. La "mala fama" o el cambio de "ambiente" al que aludía Camila son indisociables de la licuación de la identidad ferroviaria del barrio. Según Clara, obedece al arribo de "mala gente": si dos décadas antes sus habitantes eran exclusivamente ferroviarios, hacia fines de los setenta estos pasaron a ser una minoría. Pero la "mala fama" no se agotaba en las nuevas familias que transformaron la percepción del barrio, tuvo por correlato nuevas modulaciones políticas (comunicación personal, 29 de octubre de 2019).

Luego del fusilamiento de Carranza y Garibotti, el imaginario de la "Resistencia Peronista", la espera y su proyección restauradora (Guber, 1996, p. 210) no redundó, al menos no exclusivamente, en un comportamiento íntimo, cultivado puertas adentro de los hogares. El silencio o la censura pública también fueron acompañados de reelaboraciones, balances y nuevas tomas de posición. Aunque su configuración no es asimilable al "no peronismo" descrito por Carassai (2013) para la "gente común" de las clases medias, no deja de compartir con él algunos rasgos fundamentales. Entre ellos, la condena a la violencia política en su sedimentación local. En este último punto, la acción de Montoneros que en 1972 derivó en la ocupación de los terrenos aledaños que dieron origen al barrio "El Aromo", no permanece al margen de tal percepción. Hoy, este barrio es considerado una "villa-villa", donde no se puede "entrar sola", según contaban Valentín y otros vecinos.

"Ferroviario por oficio y vocación", "peronista, pero de Perón", Valentín en su juventud anhelaba el retorno del líder político al país. Convencido, en marzo de 1973, dio su voto a la fórmula Cámpora-Solano Lima, que alcanzó el 49,56\% del electorado. Esta masividad se compuso de votantes de diversas extracciones que no necesariamente se identificaban con la impronta que "la tendencia" daba al Frente Justicialista de Liberación (FREJULI). Para la mayoría de "los trabajadores, lo que importaba era el retorno de su líder al poder y no las conjeturas acerca de su conversión a una izquierda de la que, en un pasado no tan lejano, lo sabían extraño, cuando no hostill" (Carassai, 2013, p. 38). "Perón era el único que podía venir a poner orden", decía Valentín, "así no se podía seguir más, era un quilombo. Acá nomás, lo de la villa ["El Aromo"], te da una muestra. Trabajabas todo el día y no podías vivir tranquilo" (Valentín, comunicación personal, 9 de septiembre de 2020). Tres años después, el autodenominado Proceso de Reorganización Nacional no encontró en el barrio declarados opositores, tampoco épicas revolucionarias. Considerarse, como lo hacía Valentín, "peronista, pero de Perón" fue un modo más de marcar la diferencia. 
En términos generales, el regreso a la vida democrática en 1983 no mejoró la situación para los obreros del riel (Damin \& Aldao, 2015; Pagano, 2017). Las propuestas para morigerar la crisis infraestructural generada por años de desinversión no llegaron a ser consideradas y, al final de aquella década, era clara la recuperación de la senda privatizadora que signó la siguiente. La concesión de los distintos ramales a diversas empresas privadas y la decisión de dejar completamente a cargo de las provincias los distintos servicios urbanos de pasajeros redundó en que, para 1993, diecinueve de ellas quedaran sin trenes (Pagano, 2017, p. 12). Para ese mismo año, se concretó la mayoría de los despidos y "retiros voluntarios". Estos últimos, en el ferrocarril, fueron ampliamente superiores a los de cualquier otra privatización del periodo. ${ }^{6}$

El desguace y el proceso privatizador de los ferrocarriles en el marco del modelo de acumulación neoliberal que caracterizó al menemato (1989-1999) suele presentarse de dos formas. Primero, como ejemplo de la destrucción de genuinas fuentes de trabajo; como origen de "una gigantesca masa de trabajadores 'despedidos' - que sólo conocían sus respectivos oficios dentro del rubro del ferrocarril-que pasó de ser empleados a ser cuentapropistas" (Pagano, 2017, p. 19). Segundo, por sus consecuencias sociales: la aparición de "pueblos fantasmas" a raíz del cierre de las estaciones, el incremento del déficit en la salubridad pública y en los servicios sociales, el aumento de los accidentes viales y de los costos de los traslados. Veamos sus lecturas en Barrio Operario.

Las descripciones del proceso de privatización de los ferrocarriles no son blanco de críticas furibundas entre quienes en 1989 escucharon al presidente Menem afirmar "ramal que para, ramal que cierra" y, poco después, fueron despedidos o se acogieron al "retiro voluntario". Esta modalidad, vale señalarlo, preveía lo que parecía una oferta tentadora ${ }^{7}$ a la que, entre otros, intentó acogerse Milton:

Yo pedí el retiro voluntario por mis 30 años de servicio y dije "bueno, ¡voy a cobrar 30 mil dólares! Y, ¿sabe qué?, me lo rechazaron. Me quería matar, a los diez días me llega un telegrama, cesante me dejaron, me pagaron nada más que el sueldito [...]. Pero mejor, entré a trabajar en la Cámara de Diputados, trabajé 10 años ahí. Yo después me jubile en la Cámara de Diputados, yo cobro bien. (Milton, comunicación personal, 12 de noviembre de 2019)

\footnotetext{
${ }^{6}$ Entre 1991 y 1993 totalizaron 76\% de los casos, mientras que el 24\% se repartió en las empresas restantes: "la mayor parte de los 'retiros voluntarios' se acumularon en el año 1992. Ferrocarriles Argentinos implementó dicho programa en 1991, pero al año siguiente duplicó la cantidad de trabajadores 'retirados' bajo esta modalidad' (Duarte, 2002 en Pagano 2017, p. 20).

${ }^{7}$ Implicaba el pago en efectivo (en la fecha legal del salario) del sueldo del mes, del preaviso 1 o 2 meses-y de la indemnización por antigüedad.
} 
Hoy Milton se considera de "clase media o por ahí" porque, como decía, "no le tengo envidia a ningún ricachón ni le envidio a ningún pobre" (Milton, comunicación personal, 12 de noviembre de 2019). Los años de la convertibilidad no regaron de retiros voluntarios el barrio, pero en algunos casos permitieron marcar retrospectivamente el fin de una autoadscripción de clase. Veamos a qué nos referimos a partir del diálogo que sostuvimos en 2019 con Gastón, quien por entonces había comenzado a trabajar como chofer de la aplicación Uber, y Yanina, su pareja, quien percibía la Asignación Universal por Hijo (AUH):

\footnotetext{
Investigadora: ¿Ustedes consideran que pertenecen a una clase social?

Gastón: Sí.

Investigadora: ¿A cuál?

Gastón: A la baja, la clase media ya no existe, desapareció, estás en la baja o en el alta.

Investigadora: ¿En algún momento te sentiste de clase media?

Gastón: Sí, obvio, hace muchos años atrás.

Investigadora: ¿Cuándo?

Gastón: En el tiempo cuando estábamos con el dólar 1 a 1. Muchos lo critican a Menem [...]. Yo en tiempos de Menem tenía 14 o 15 años y ya podía laburar, yo salía a laburar y me acuerdo de laburar en una verdulería que nos pagaba 50 pesos. Yo alquilaba y vivía solo con 50 pesos, cuando el pan costaba 50 centavos y era que vos podías vivir y no es que salías a buscar trabajo y hacías cola, te venían a buscar a tu casa para laburar. Muchos lo critican [a Menem], pero los que vivieron esa época tenían trabajo [...]. Mi viejo también, cuando le dieron el retiro voluntario, le pagaron todo en dólares. (Gastón, comunicación personal, 21 de octubre de 2019)
}

El padre de Gastón invirtió el dinero que percibió por su retiro voluntario en la compra de dos locales de cuya renta vive - de acuerdo con Gastón, mejor que él- hasta el presente. Si bien Gastón contempla que durante el proceso privatizador no pudo ingresar a trabajar en el ferrocarril, los motivos no son explícitamente imputados al gobierno: "cuando Menem privatizó el ferrocarril, por ley [de haber puestos de trabajo disponibles] tenían que tomar al hijo de un ferroviario, y trajeron a los amigos, al primo, al tío y lo que menos hicieron fue cumplir con la ley esa... Era una empresa alemana" (comunicación personal, 21 de octubre de 2019).

Más que el registro del propio empobrecimiento, los noventa añadieron otras marcas entre las ya minoritarias familias ferroviarias de Barrio Operario. La primera, y más notable, es la pregnancia de un posicionamiento antiestatal y antigremial que logró imponerse a partir de la privatización. Si bien el desequilibrio y la ineficiencia del Estado para gestionar el sector, así como la falta de legitimidad gremial para representar los intereses de los trabajadores estaban presentes desde hacía tiempo, en los noventa ambos sentires ganaron densidad y se proyectaron excediendo el caso específico de los ferrocarriles. El antiestatismo configuró parte de la distinción al interior de un barrio que, como explicaba Livio, más 
allá de la zona de "los chalets", siguió expandiéndose. El "fondo", los "pasillos" y todas las casas que comenzaron a instalarse, condensan desde entonces la suma de todos los males explicados por la llegada de la "droga", los enfrentamientos entre bandas y las escaramuzas policiales, pero también por la presencia asistencial de la política y del Estado. "Transas", "manzaneras", "punteros" y "piqueteros" surgen de ese universo como nuevos actores que impactaron decididamente sobre las representaciones del barrio, las autoadscripciones de clase y las identificaciones políticas. Veamos algunos de los vínculos entre estas tres dimensiones.

Salvo por un breve periodo a fines de los ochenta cuando residió en otro municipio cercano, Beatriz transcurrió sus casi setenta años en el barrio. Hija de un trabajador ferroviario, completó la escuela primaria en un establecimiento nocturno y comenzó a trabajar a los catorce años. A los dieciocho se casó con un linchero del Belgrano al que conocía desde la infancia. En los noventa, el sueldo de su marido, muy bajo para la tarea agotadora que realizaba, no alcanzaba para cubrir los gastos fijos del hogar, situación que se hizo más acuciante cuando se separó de él "por mujeriego". A comienzos de los noventa comenzó a trabajar en la industria del calzado y, luego, en una empresa de servicios de la zona, empleo por el cual hoy recibe una jubilación, su principal ingreso. Después de mucho esperarlo, logró obtener la escritura de su casa, una de las 64 unidades habitacionales que fueron adjudicadas por intermedio del Programa Arraigo para la regularización de barrios informales, creado por el Poder Ejecutivo en 1991.

En 1989 Beatriz votó a Menen, pero rápidamente aclara que siempre votó a "la lista de los peronistas", que no fue por la escritura de su casa porque no imaginaba obtenerla, y que a ella no le compran el voto. Todavía recuerda la tarde de junio de 1996 cuando una señorita golpeó a su puerta para decirle "el trámite ya está", que era propietaria del chalet donde crio a sus 5 hijas e hijos. Ninguno de ellos trabaja en el ferrocarril porque, con el tiempo:

La entrada se puso más exigente. Antes vos entrabas por familiar, hijo, tío, primo... y listo. Ya después tenías que tener secundario completo. Mi padre y mi exmarido tenían primario y entraron así, pero después no, para cualquier puesto, secundario completo. Entonces mis hijos no entraron, uno es el camionero que vos viste acá y, las chicas trabajaron de varias cosas, en una empresa de limpieza, de vendedora... y más cosas que ni me acuerdo. (Beatriz, comunicación personal, 23 de septiembre de 2020)

Tiempo antes, Beatriz nos contó lo difícil que era conseguir trabajo para los jóvenes, "los contrataban por tres meses y, luego, no les renovaban el contrato" (comunicación personal, 29 de octubre de 2019). Las experiencias asociadas a la flexibilización y la precariedad laboral no fueron ajenas a su familia. De hecho, le permitían explicar las razones por las cuales dos de sus hijos "no tuvie- 
ron otra" que construir sus hogares en el amplio terreno de su casa: "era eso o meterse en la villa", es decir "meterse en un terreno de los que quedaban", situado a una cuadra de su flamante propiedad. De ahí para allá, como suele decir y compartir con otros vecinos, "es otro mundo".

El desborde del perímetro original del barrio peronista no sólo permite advertir límites materiales, también trastoca las autopercepciones de clase que derivan en fricciones políticas. Danilo, quien llegó al barrio a sus tres años y lleva más de 35 trabajando en el ferrocarril, directamente excluye de su delimitación aquellas zonas: “a [Barrio Operario] se agregó lo demás. Allá en el fondo también dicen [Barrio Operario], yo me enojo y digo 'no, eso no es [Barrio Operario]; [Barrio Operario] es este', ese es barrio no sé... 'barrio Ruedita'” (comunicación personal, 1 de noviembre de 2019). Beatriz sitúa allí a quienes "estaban en la lona, mal, mal" y necesitaban "que un puntero les diera un colchón" (comunicación personal, 23 de septiembre de 2020). En nuestro diálogo, agradecía no haber necesitado nunca que le dieran algo. Fue, incluso, más explícita:

Beatriz: ¿Ves esa casa, la de dos pisos, blanca, de la esquina? Bueno, ahí la mujer era "manzanera". Repartía leche, colchón... Andaba con [Melchor] Posse. ${ }^{8}$

Investigadora: ¿Pero Posse no era radical?

Beatriz: Sí, creo que sí...

Investigadora: ¿Entonces las manzaneras no eran todas peronistas?

Beatriz: No. Sí, los punteros son todos peronistas acá, pero viven todos ahí, en esa parte que te digo. (comunicación personal, 23 de septiembre de 2020)

A mediados de los noventa, "una 'nueva' forma de hacer política social puso en relación diversos actores e instituciones" (Masson, 2004, p. 24). Además de haber encabezado las listas legislativas de 1997, el Estado provincial nunca antes había incorporado una cantidad tan importante de mujeres en la participación y ejecución de programas sociales (Masson, 2004, p. 15). Entre ellos, el "Plan Vida", encabezado por Hilda "Chiche" Gonzáles de Duhalde, y su imponente red de manzaneras, fue quizás el más resonante y aquel que, pese a la pretendida "apoliticidad" requerida por la nueva "gestión social" (Masson, 2004, p. 97), se tornó un hito en la estigmatización del "asistencialismo" o "clientelismo" -unívocamente asociado al peronismo-y sus destinatarios. Aun hoy, en el barrio resulta difícil quebrar esta asociación. Karen, hija de un jubilado ferroviario, volvía sobre ella: "Si no sos peronista acá, sonaste [...]. Acá siempre ganó Posse, pero creo que no es peronista, pero es como peronista porque siempre estuvo acá" (comunicación personal, 29 de octubre de 2019).

\footnotetext{
${ }^{8}$ Melchor Posse fue un importante dirigente de la Unión Cívica Radical (UCR), intendente de San Isidro por cinco periodos, entre 1958 y 1962 y entre 1983 y 1999. Fue también candidato a vicegobernador de la provincia de Buenos Aires por la UCR en 1999.
} 
En los noventa, al "otro mundo", en palabras de Beatriz, o a "barrio Ruedita”, según Danilo, llegaron Sara y sus hijos. Luego de vivir en Fuerte Apache, se instalaron en el terreno que el padre de Sara compró una década antes, en una de las pocas calles asfaltadas por la que circulan dos líneas de colectivos. En tres meses -a instancias de múltiples gestiones ante el juzgado de menores y el área de acción social del municipio- logró construir su casa. Aunque no pudo terminarla, llegar al barrio implicó una mejora sustancial que sintetizaba en una frase contundente, mientras señalaba el asfalto: "estoy en San Isidro, yo acá cotizo en dólares". Por entonces, Sara trabajaba como "seguridad" de un importante banco. En Fuerte Apache integró una Unidad Básica en la que trabajaba "con los chicos", pero al llegar al barrio no se involucró con "ningún político". Tiempo después, hacia fines de la década y durante la crisis de 2001, "no le quedó otra". Desde entonces, tiene que buscar "ayuda", "pelear por la mercadería, pelear por los medicamentos" (Sara, comunicación personal, 10 de octubre de 2019). Aunque "progresó", todo lo mencionado la lleva a ubicarse en la "clase baja" y a establecer distinciones para el propio barrio:

Mirá, los empleados ferroviarios se creen dueños del... los empleados de la municipalidad se creen dueños del barrio, los empleados que están en cuestiones, porque están estudiando en la universidad, se creen más. Y están con los pies llenos de barro, allá atrás yo tengo a cuantos... Se creen más que vos, ¿viste? Se le vuelan los pajaritos [...]. Hay como una escalera social, primero ferroviarios, después municipales, después los que trabajan en una empresa importante, que se creen la gran cosa, por ejemplo, policía, navegación. (Sara, comunicación personal, 10 de octubre de 2019)

La enumeración resulta esclarecedora. Para fines de los noventa, Barrio Operario cambió su paisaje, (des)bordaba sus límites y, con ello, las autoadcripciones de clase que ya no se ajustaban únicamente a la "clase obrera" o "trabajadora" derivada de la identificación ferroviaria que paulatinamente configuró una suerte de "aristocracia plebeya", que se confirmó como tal en lo que era percibido como excedente, no solo perimetral. En estas circunstancias de desbordes y excesos, no solo los y las recién llegadas debieron procurar "ayuda" o se beneficiaron de alguna acción estatal. Sin embargo, no es la condición, sino la cualidad de la recepción lo que parece modificar relacionalmente la autopercepción de clase y su consecuente valoración moral y política. Entre familias como la de Beatriz, que por medio del Plan Arraigo lograron la titulación y escritura de sus casas, y familias como las de Sara que, por medio del Plan Vida, pudieron obtener mercaderías y bienes básicos, habitaba -y habita- un "mundo" cuyas diferencias tensan, como veremos a continuación, las identificaciones políticas. El "mundo de diferencia" perceptible desde los setenta, agudizado en los noventa, devendrá "grieta" en los 2000. 


\section{PROGRESO SIN FIN (2003-2019)}

Luego de la crisis de 2001 y del arribo a la presidencia de Néstor Kirchner, el Estado introdujo cambios en el modelo de desarrollo económico-social a través de una reorientación hacia políticas de protección del mercado interno, industrialización por sustitución de importaciones y redistribución del ingreso. En esta "sociedad posneoliberal" (Kessler, 2016, p. 9), dos experiencias marcaron el contraste respecto de los noventa para los sectores populares: la "relaborización", dado el incremento del número de trabajadores en las fábricas, y la "recolectivización" reflejada en el fortalecimiento de los sindicatos en su densidad y capacidad para negociar los salarios (Semán \& Ferraudi Curto, 2016). En el Área Metropolitana de Buenos Aires (AMBA), el alza de los ingresos de los hogares y la incidencia de las políticas públicas introdujeron variaciones en las condiciones habitacionales (Semán \& Ferraudi Curto, 2016, p. 148). Sin embargo, esto no derivó en la homogeneización de los espacios urbanos, donde "persisten formas agudas de segregación y fragmentación socioespacial” (Kessler, 2016, p. 15).

Más allá del empeño en las distinciones y fronteras que advierten sus vecinos y vecinas para derivar de ellas distintas autoadscripciones de clase, para comienzos de este siglo y de acuerdo con las normas de ordenamiento urbano y territorial, Barrio Operario era tipificado como uno de los diez asentamientos irregulares del partido de San Isidro (Grahl, 2008). A más de cincuenta años de su creación las calles seguían siendo de tierra, no contaba con red cloacal ni gas natural, tampoco con sistema de recolección de residuos urbanos y, en caso de una emergencia médica, las ambulancias no podían ingresar por la estrechez de sus vías y pasajes. En los años siguientes varias de estas condiciones habitacionales comenzaron a cambiar.

Entre 2004 y 2016, no hubo prácticamente una sola de las grandes políticas públicas implementadas durante el ciclo kirchnerista que no hubiera alcanzado al barrio. ${ }^{9}$ La transformación material fue radical: se realizaron obras de apertura de calles, saneamiento y pavimentación, se amplió el tendido de gas natural, se construyeron viviendas y se entregaron los títulos faltantes de propiedad de los terrenos. Aun cuando los grados de avance son diversos, ya no quedan viviendas en el barrio que no sean de material: abarcan desde los chalets de los cuarenta -con aire acondicionado, pileta y parque- a las casas de dos o tres pisos, en

\footnotetext{
${ }^{9}$ Entre ellas, el Plan Nacional de Obras Públicas y el Plan Federal de Viviendas (2004), la Asignación Universal por Hijo (AUH, 2009), el Plan de Inclusión Previsional (2005, PIP) y el Programa de Crédito Argentino del Bicentenario para la Vivienda Única Familiar (PRO.CRE.AR, 2012).
} 
terrenos sin fondo. La política previsional y los programas de transferencia condicionada de ingresos permitieron que muchas de las mujeres de los ferroviarios retirados accedieran a la "jubilación por ama de casa" y, las jóvenes madres, a la AUH.

Las obras públicas, el incremento progresivo de la capacidad de consumo y de acceso a distintos bienes y servicios para amplios sectores de la población delinearon hacia fines del segundo mandato de Cristina Fernández de Kirchner la definición del periodo como "década ganada". Evidencia de ello era el ensanchamiento de las clases medias o la existencia de una clase media emergente. Sin embargo, las evaluaciones respecto del desembarco masivo de la planificación estatal y su impacto sobre las autoidentificaciones de clase no resultan tan lineales. Cuando nos detenemos en ellas observamos que, incluso entre quienes podrían testimoniar la movilidad en los términos en que fuera enunciada por el balance de la gestión de gobierno, las autoadscripciones de clase no necesariamente resultan releídas a partir de los datos estadísticos contemplados en él. Por diversas razones, los patrones ingreso, consumo y acceso a derechos resultan una condición necesaria pero insuficiente para alterarlas, tal como había sucedido en otras ocasiones.

A riesgo de simplificar lo que desarrollaremos a continuación con mayor detalle, anticipemos que en Barrio Operario las trayectorias de movilidad ascendente, que desde la propia perspectiva reunirían las evidencias necesarias para propiciar transformaciones en la autopercepción de clase, enfrentan una serie de dificultades. Estas surgen de una compleja combinación que conecta la territorialización -una suerte de identidad barrial indeleble- y la moralización de la polarización política cifrada entre sentimientos de gratitud, reconocimiento, traición y deslealtad. Pero, fundamentalmente, coinciden en una percepción ampliamente compartida que anula el horizonte de la movilidad sea como fuere considerada. Las afirmaciones respecto del fin o la inexistencia de las clases medias que escuchamos una y otra vez entre las y los vecinos de Barrio Operario marcan no sólo la encrucijada que supone que aquello a lo que se desea acceder ya no existe. Las referencias a la extinción de las clases medias son un enunciado político en sí mismo. Sobre tal percepción anidan sanciones y sobrevienen desencantos cuya resolución es más que la ratificación de la extrema polarización. Si las clases medias fueron un horizonte, además de un actor protagónico de la construcción crítica de la democracia, establecer su extinción es, también, un modo de evidenciar el profundo malestar en la representación política que abre paso a las alternativas partidarias.

Danilo, ferroviario desde hace 35 años y segunda generación de su familia en el rubro, avala los principales tropos en los que se asienta la "década ganada". En términos "objetivos", su balance podría ilustrar la campaña del kirchnerismo con vistas a las elecciones que colocaron en 2015 a Mauricio Macri en la presidencia: 
Siendo ferroviario, del 2013 al 2015 me saqué el auto, porque lo saqué a pagar. Yo, en mi puta vida, pensé tener un auto 'Cero Kilómetro', ni el auto que tengo. Estas políticas [del gobierno] me han ayudado a eso, a poder tener un auto, a hacer esa pieza, la otra pieza, irme de vacaciones todos los años y con mis hijos, con los tres [...]. Yo he trabajado desde los 14 años, toda mi vida trabajé [...] y se mejora o se empeora según las políticas [...]. Tus mejoras van a ser mejoras por las políticas de los gobiernos. (Danilo, comunicación personal, 1 de noviembre de 2019)

Tal vez por la impronta no meritocrática y colectiva de su lectura, las evidencias relativas a las transformaciones materiales no trastocan la autopercepción de clase propuesta. Posiblemente porque al desplazamiento se uniría una potencial desafiliación política que no está dispuesto a asumir:

No sé cuál sería la clase en que estoy [...]. El viejo que está al frente, antes que estuviera Macri, tenía la parrilla llena [...]. De a poco fue pasando el tiempo y no hay nadie [en la parrilla] y ¿A quién voto? [...]. No puedo entender [...]. Se cree dueño de la mansión, pero duerme afuera, como el perro [...]. Nos podemos quejar de un montón de cosas del peronismo, pero yo no voy a cambiar, ya está comprobado. Yo, clase trabajadora. (Danilo, comunicación personal, 1 de noviembre de 2019)

La impugnación de la combinación de clase e identificación política creerse más de lo que se es, votar al macrismo- no sucede sin costos. En el caso de Danilo supone, en el mismo movimiento, lealtad y fidelidad -como inmovilidad- en la autopercepción de clase. Pero también es parte de una crítica por elevación a las fluctuaciones políticas y valores asociados a las clases medias. Héctor, diplomáticamente, avanzaba esta lectura como sigue:

Con los pobres estoy yo... con los que sufren [...]. Yo sería clase baja [...]. Yo siempre tuve la costumbre, que me enseñaron a mí siempre... La clase media, no es por despreciar, [pero] siempre nosotros, la clase social nuestra es así, humilde, sincera. (Héctor, comunicación personal, 10 de octubre de 2019)

Cuando se trata de incorporar a las autopercepciones de clase las transformaciones del barrio, algunos vecinos como Mariano destacaban una dimensión del desarrollo asociado al ciclo kirchnerista, no siempre referenciada a la hora de considerar las subjetivaciones de las mejoras materiales:

Antes que se urbanice todo se acercaba mucho más el vecino uno a otro [...]. Diciéndole, por ejemplo, "tus hijos se portan mal, fijate lo que hace". Y te atendían [...]. Antes el vecino estaba más pegado, se relacionaban más los vecinos, le avisaba al vecino si el hijo estaba tomando cocaína en la esquina, por ejemplo. Ahora no, como que cada uno hace la suya. (Mariano, comunicación personal, 21 de octubre de 2019)

Una lectura rápida podría inscribir las palabras de Mariano en cierta idealización del pasado. Sin embargo, cuando las pensamos en los términos de autoadscripción de clase e identificación política, lo que Mariano parece poner en consideración es el lazo social y el espacio comunitario quebrado por la lógica 
individualizadora del progreso que, a su vez, traería aparejado "confusiones" relativas a la percepción de la estructura social y del lugar que se ocupa en ella. Para Mariano, a la par de la apertura de calles y pasajes, era necesaria otra gestión -no menos importante- que permitiera "sacar a los chicos de la esquina [...], darles otra formación, otra educación, para que sean otra clase de personas" (comunicación personal, 21 de octubre de 2019). Esta distinción es clave para comprender el modo en que inscribe al grueso de los habitantes del barrio en una "clase baja confundida".

Resulta inquietante que, entre todos y todas nuestras interlocutoras, Mariano sea uno de los pocos vecinos que en términos "objetivos" podría aproximarse a las clases medias: hijo de un trabajador ferroviario, es dueño de tres propiedades, reside una parte del año en el barrio y otra en Tucumán. Soltero y sin hijos, su pensión por discapacidad y la renta de una de sus casas le permite vivir sin sobresaltos. Aun así, opta por una definición de clase que no se limita al ingreso y el poder adquisitivo, afirmándose desde otros capitales que habilitan, por ejemplo, formas específicas de expresarse y relacionarse. Es en este punto que, desde su perspectiva, los progresos en el barrio hicieron que las personas se "confundan" respecto de su posición de clase y voten en consecuencia:

Mariano: Acá hay gente que se confundió [...]. ¿A vos te parece, un lugar que lo hizo el peronismo? La cuna del peronismo. Vino el gobierno anterior, los dignificó, ¿y votó el $71 \%$ a Macri?

Investigadora: ¿Acá votaron a Macri?

Mariano: Sí, el 70\%. ¿Por qué? Porque los desafectaron del trabajo en el gobierno de Menem, cuando estuvo Cristina empezó a dar laburo, en el ferrocarril se pudieron comprar una camioneta de alta gama y se creyeron. (Mariano, comunicación personal, 21 de octubre de 2019)

Más allá de la veracidad del porcentaje señalado, lo que importa aquí es la intención por parte de Mariano de señalar y sancionar lo que advierte como una masiva e injustificada desafiliación social y política. Su condena moral, encaramada en cierta falta de gratitud, define como confusión las transformaciones políticas asociadas a la movilidad social que, en otras coyunturas, se reforzaron mutuamente. Vale detenerlos en las trayectorias y reflexiones de Leo y Bernarda para advertir las complejidades que estas operaciones conllevan.

Tras finalizar el nivel secundario y comenzar a estudiar una carrera terciaria que terminó por aburrirlo, Leo ingresó al mundo ferroviario por la "puerta grande". Nacido y criado en el barrio en el seno de una "familia ferrocarrilera" por tres generaciones, su identificación peronista está indisociablemente unida a este parentesco laboral. En 2014, comenzó a desempeñarse como preconductor 
y luego como maquinista, puesto que define como "uno de los regalos más lindos que Dios me dio". Además de la fascinación que desde niño le despertaron las locomotoras, ser maquinista lo coloca como parte de un sindicato altamente institucionalizado y con un vínculo diferencial con el resto de los trabajadores ferroviarios -una "aristocracia obrera" (Falcón, 1986) - que marca en el barrio un horizonte de prestigio y ascenso social tan anhelado como difícil de concretar. A sus 29 años, construyó y equipó su casa, creó junto a su hermano una pequeña empresa de fletes dotada de dos camionetas y pudo enviar a una de sus dos hijas a una escuela privada. Todo esto hace que Leo explique como sigue su autopercepción de clase:

Económicamente no me siento en la clase baja. No me gusta mentir, soy sincero, no me siento clase baja, me siento en una clase que uno está progresando [...]. Pero siempre me voy a sentir de lo que es la parte más abajo, porque es la gente con la que uno se codea, habla, con la gente que uno se conoce. Es así, o sea, yo siempre voy a estar en el barrio. (Leo, comunicación personal, 2 de noviembre de 2019)

Las reflexiones por la negativa propuestas por Leo complejizan e, incluso, obstaculizan las definiciones de clase por ingreso. Su autoadscripción es relacional en un sentido bastante específico, se ajusta a las fronteras del barrio y el habitus que le permiten trazar. Así, en el mismo movimiento, las políticas públicas -en la óptica del esfuerzo personal- que transformaron Barrio Operario durante el ciclo kirchnerista resultan en una cuestión más de forma que de contenido, trastocando la escala y el progreso familiar como base estructurante del mundo popular:

A partir del 2003 hubo un plan de vivienda que se refacciono todo y ahí el barrio cambió bastante en cuanto a la fisonomía, lo que es la estética del barrio. Después, gente que progresó, gente que no, gente que tuvo las herramientas y las supo aprovechar [...]. Uno le puede brindar una casa, le puede brindar oportunidades, pero si eso no es un trampolín para que vos progreses uno se queda estancado [...]. Yo ando mucho por la calle y uno conoce otros barrios y acá la verdad es que estamos bastante bien. Siempre digo, mejor vivir dentro del barrio a vivir fuera del barrio, porque uno se siente más inseguro [afuera del barrio]. (Leo, comunicación personal, 2 de noviembre de 2019)

Como Leo, la autoidentificación de clase propuesta por Bernarda contempla un criterio que, aun cuando permitiría señalar una movilidad intergeneracional ascendente, la mantiene en los márgenes de la "clase baja". Su trayectoria responde a la lógica propuesta por Leo y, simultáneamente, encarna una de las principales reivindicaciones del ciclo progresista: hija de una empleada doméstica, además de integrar un cuerpo de danzas folclóricas y trabajar como telefonista en una pizzería, accedió a una casa de material que comparte con su hermana y sus respectivos hijos, y está a poco de graduarse como licenciada en educación. Esto último, más que promoverla, confirma su inscripción previa: 
Investigadora: ¿Considerás que perteneces a alguna clase?

Berenice: A la clase baja.

Investigadora: ¿En algún momento estuviste en otra clase?

Berenice: No, para nada [...]. Se nota, comparándote te das cuenta, pasa mucho en la facultad [...]. Con mi hermana somos la primera generación que estudia en la facultad de toda mi familia, eso tiene un montón que ver. Cuando tenés compañeros que son todos los padres profesionales y tienen un acervo cultural inmenso y, bueno... No desmerezco lo que yo traigo porque es re-importante, pero te das cuenta ahí las diferencias de clase. (Berenice, comunicación personal, 21 de octubre de 2019)

Los signos de distinción asociados al "progreso" sumaron en el barrio a la polarización como modo de aproximación crítica a la gestión de la política, comúnmente denominada "grieta". Muy lejos ya de su configuración en torno a las políticas para con el campo y las disposiciones fiscales, la grieta trama las experiencias asociadas a las desigualdades más próximas, menos abstractas. Sin advertirlas, sería sumamente difícil comprender las autoadscripciones de clase propuestas por Danilo, Leo o Berenice. Su dimensión dialógica, aquella que las conecta con lecturas como las de Sara, es lo que permite interpretar los modos en que se alimentan autoidentificación de clase e identificación política:

Investigadora: ¿Te consideras perteneciente a una clase social?

Sara: Sí, baja. Ya no hay clase media, hay clase alta y baja. La clase media está totalmente excluida al momento que tenés que ir a buscar ayuda a un lugar, que tenés que pelear por la mercadería, que tenés que pelear por los medicamentos. (Sara, comunicación personal, 10 de octubre de 2019)

Con una capacidad de síntesis metafórica admirable, Sara exploraba distinciones y sanciones morales que paradójicamente se atribuyen a los repertorios de la clase que excluye, cuyo fin sentencia:

Nosotros somos como los hebreos, ellos son el Alto Egipto: hay mucha diferencia [...]. Ves a todos los hijos de ferroviarios, a la vuelta, te encontrás hasta con un Audi ¿Sabes lo que es un Audi? Tienen Audi y es ferroviario, vive en uno de los pasajes [pero] tienen un Audi, Hyundai, tienen camionetas espectaculares. Porque tienen eso ya te miran. (Sara, comunicación personal, 10 de octubre de 2019)

Aquí, la autoadscripción de clase conlleva una modulación política que contempla los principales tópicos de la agenda mediática centrada en los males del "populismo" y los hechos de corrupción atribuidos a la gestión kirchnerista, pero no ancla ni procura verosimilitud exclusivamente en ella, sino en la biografía familiar que anuda su desencanto:

Pienso que esto viene de antes, no es de ahora. Viene de Néstor Kirchner, porque de un momento a otro no se puede haber vaciado la Argentina. Primero, no hay justicia. ¿Cristina Kirchner tendría que haber estado presa hace cuánto? [...]. Están liberando a gente que ellos ayudaban en las campañas políticas. Mi hijo, por ejemplo, el más grande, él tenía un sueldo de piquetero de nueve mil pesos hasta que asumió este Macri, más el 
salario de los chicos [la AUH]. No trabajaba, arreglaba celulares en la casa, no estudiaba. Yo le decía "¿Por qué no trabajás en otro lado?”. "Ni me gasto”, dice, todo era por política. A mí me daría vergüenza, le dije, tener un bono de piquetero. (Sara, comunicación personal, 10 de octubre de 2019)

Yanina y Gastón siguen y suman a una lógica similar respecto de la autopercepción de clase:

Investigadora: ¿Ustedes consideran que pertenecen a una clase social?

Gastón: Sí.

Investigadora: ¿A cuál?

Gastón: A la baja, la clase media ya no existe, desapareció, estás en la baja o en el alta. (Gastón, comunicación personal, 21 de octubre de 2019)

La percepción binómica de la estructura social y su inserción en ella, compartida por otros vecinos que también fueron -en la jerga estatal- "beneficiarios" de las políticas impulsadas durante el ciclo kirchnerista, lejos de descansar cómodamente en muestras de gratitud acríticas, agencia sus propias desesperanzas. La desconfianza, la ineficiencia y la corrupción no están en la televisión: se sitúan y dirimen en el barrio. Conversando acerca de la puesta en marcha del Plan Federal de Viviendas que les permitió obtener su primera casa, Yanina y Gastón decían lo siguiente:

Yanina: Los que hicieron las casas [del Plan Federal de Viviendas] en todo el barrio son un desastre. Gente de Paraguay que no sabía agarrar ni una cuchara. Una vez vi al paraguayo con el rodillo, estaba preparando la pintura y estaba por llover, “¿cómo vas a pintar -le dije- si está lloviendo? Y le digo "¿por qué no dejas mejor la pintura y pintamos nosotros?”. Y se lavó toda la pintura.

Gastón: Se comieron toda la guita... Te soy sincero, ninguno cree en ningún político, la gente perdió la confianza [...]. No lo hacían de corazón... los que hacen política lo hacen por la guita, no hay que ser hipócrita [...]. Acá no hay punteros políticos que digan 'ime voy a ocupar de la gente!' No te digo que regalen todo, pero si te dan para la gente, para repartirle a la gente... No te agarres para vos, no vendás. Había un tipo que descargaba mercadería de [Presidencia de la] Nación a los negocios y venían otras personas de otros lados a comprarle. Te lo digo porque yo descargaba el camión, a mí me daba mercadería porque yo descargaba el camión, no te estoy diciendo por decírtelo. (Yanina y Gastón, comunicación personal, 21 de octubre de 2019)

A partir de los éxitos electorales de 2011, el kirchnerismo apostó por una polarización que, "apuntando a una creciente homogenización de la propia fuerza política", tuvo efectos contradictorios Grimson (2019, p. 310). Uno de ellos fue empujar a la oposición a una coalición que, con cada vez más insistencia y éxito, empleó la polarización para asociar al kirchnerismo, al sindicalismo y a los sectores populares asumiéndolos como sinónimos de ladrones e inmorales. Esta polarización, que reconstituye con nuevas complejidades los usos políticos antiperonistas y no son una novedad en Argentina, permite explicar -al menos en parteel cambio de rumbo, iniciado con el arribo a la presidencia de Mauricio Macri. 


\section{PALABRAS FINALES}

A lo largo de estas páginas, Barrio Operario fue el escenario que permitió identificar y analizar la localización contradictoria de procesos macro- y mesoestructurales de carácter variado (económico, social, simbólico), su relación con las autoidentificaciones de clase -o la "clase subjetiva"- y las identificaciones políticas que estas habilitaron en diversos momentos de su historia, ligada al ferrocarril y al peronismo.

Esta relación no siempre se comportó de igual modo. En los primeros años del barrio, coincidentes con la "estrategia justicialista" de desarrollo, la modificación de la autopercepción posicional de las familias llegadas del norte del país encontró particularmente en el acceso a la vivienda la vía de incorporación a la "clase trabajadora" que completó y agenció una identificación peronista preexistente. Esta correlación se mantuvo consistente hasta el golpe de 1955, concretamente, hasta la "Masacre de José Léon Suárez". En su marco, el fusilamiento de dos vecinos, además de un masivo encuentro con la represión ilegal, señaló el inicio de una frontera política que anticipó una frontera en la autopercepción de clase.

Luego de décadas de paulatina movilidad ascendente desprovista de reconocimiento exógeno, cuando el barrio "desbordó" su perímetro original y devino "villa", el establecimiento de bordes y zonas por parte de las familias ferroviarias -su traducción en posiciones sociales objetivadas en el espacio- trajo consigo la configuración de una suerte de una aristocracia plebeya dispuesta a no ceder, en plena "estrategia aperturista", ante las igualaciones que comprometían su identificación política. Tomando por caso un barrio segregado del gran Buenos Aires, Segura analizó el modo en que "oposiciones sociales objetivadas en el espacio físico como adentro-afuera, delante-detrás, alto-bajo, tienden a reproducirse en el lenguaje y las prácticas como principios de visión y división, en definitiva, en categorías de percepción y clasificación de objetos, lugares y personas" (Segura, 2009, pp. 55-56). En Barrio Operario, la articulación entre las categorías espaciales operando como categorías sociales y las moralidades que organizan las interacciones en clave "nosotros-ellos" (Segura, 2009, p. 56), parece responder a los intentos de establecer bordes -como límites-al desborde -en tanto rebasamiento- de su perímetro, autoadscripción e identificación fundacional.

Los últimos años coincidentes con el ciclo "posneoliberal" evidencian que no siempre las transformaciones materiales en las condiciones de vida trastocan los autoposicionamientos en la estructura social. A lo largo del tiempo, las diversas articulaciones entre autoadscripciones de clase e identificaciones políticas registradas en Barrio Operario resultan, entre otras cuestiones, vías de acceso 
a los agenciamientos de los actores, concretamente a las dinámicas respecto de la constitución de sus deseos y formas de vida, de la ponderación de lo público y las concepciones de lo privado. Esto, que en principio puede resultar obvio, dejaría de serlo si atendemos a las lógicas que subyacen en las cartografias del barrio propuestas por sus residentes cuyas movilidades -más o menos evidentes, más o menos consistentes-ya no parecen referenciarse en la estructura social tripartita que informan las ciencias sociales. Los desencantos y desesperanzas que esto acarrea sitúan las autopercepciones de clase en un "progreso sin fin", sin un destino factible. Ante este desencanto, si trastocar la autopercepción de clase resulta por las diversas razones que vimos hasta aquí inviable, posiblemente, lo que cabe, es accionar sobre las identificaciones políticas.

Desde ya, esto último no implica desconocer las recientes conquistas alcanzadas por los habitantes de Barrio Operario en términos de transformaciones de clase, sino que invita a observar que incluso su reconocimiento se confronta y dialoga con diversas encrucijadas derivadas de la masiva percepción de una estructura social binómica que se corresponde con un escenario político polarizado. Así, navegando en pares sociales y políticos opuestos, los cambios en las identificaciones políticas, más que abrevar en las modificaciones en las autopercepciones de clase, fundan -desesperanzadamente-algo de su confirmación.

\section{BIBLIOGRAFÍA}

Adamovsky, E. (2007). Peronismo y "clase media": De las ilusiones al resentimiento (1944-1955). Entrepasados, (31), 117-139.

Adamovsky, E. (2008). Esa incómoda presencia: La izquierda y la 'clase media' en la Argentina, 1891-1943. Políticas de la Memoria, (8/9), 239-248.

Adamovsky, E. (2009). Historia de la clase media argentina: Apogeo y decadencia de una ilusión (1919-2003). Planeta.

Adamovsky, E. (2013). Clase media: Reflexiones sobre los (malos) usos académicos de una categoría. Nueva Sociedad, (247), 38-49.

Aldao, J. (2018). Obreros, ferroviarios y... ¿peronistas?: Institucionalización y dinámica identitaria en la Unión Ferroviaria. UNQ.

Altamirano, C. (1997). La pequeña burguesía, una clase en el purgatorio. Prismas - Revista De Historia Intelectual, 1(1), 105-123.

Álvarez Leguizamón, S. (2018). Geopolítica nacional, estructura social y racismo. In S. Álvarez Leguizamón, A. Arias \& L. Muñiz Terra (eds.), Estudios sobre la estructura social en la argentina contemporánea (pp. 333-392). PISAC-CLACSO.

Auyero, J. (2001). La política de los pobres: Las prácticas clientelares del peronismo. Manantial.

Benza, G., Iuliano, R., Álvarez Leguizamón, S. \& Pinedo, J. (2016). Las clases sociales en la investigación social de la Argentina (2003-2014). In S. Álvarez Leguizamón, A. Arias \& L. Muñiz Terra (eds.), Estudios sobre la estructura social en la argentina contemporánea (pp. 143-214). PISAC-CLACSO. 
Bonazzi, M., Ferraudi Curto, M. C., Moriconi, M., \& Semán, P. (2017). La Matanza: Sin lugar para arrepentidos. Anfibia. http://revistaanfibia.com/cronica/la-matanza-sin-lugar-arrepentidos/

Carassai, S. (2013). Los años setenta de la gente común: La naturalización de la violencia. Siglo XXI.

Contreras, G. (2009). Ferroviarios. Un capitulo de sus luchas: Las huelgas ferroviarias de fines de 1950 y principios de 1951. V Congreso de Historia Ferroviaria, 14-16.10.2009, Palma. https://www.docutren.com/HistoriaFerroviaria/PalmaMallorca2009/pdf/030114_Contreras.pdf

Dalle, P. (2016). Movilidad social desde las clases populares: Un estudio sociológico en el Área Metropolitana de Buenos Aires 1960-2013. Instituto de Investigaciones Gino Germani, UBA.

Damin, N., \& Aldao, J. (2015). Sociología, historia y memoria de los pueblos ferroviarios. ICPBA.

Elias, N., \& Scotson, J. (1994). The Established and the Outsiders: A Sociological Enquiry into Community Problems. SAGE. https://doi.org/10.4135/9781446222126

Falcón, R. (1986). El mundo del trabajo urbano (1890-1914). CEAL.

Ferraudi Curto, M. C. (2006). Ni Punteros, Ni Piqueteros: Urbanización y política en una villa del conurbano. Gorla.

Garulli, L., Caravallo, L., Charlier, N. \& Cafiero, M. (2000). Nomeolvides: Memoria de la resistencia peronista 1955-1972. Biblos.

González Bombal, I., \& Svampa, M. (2001). Movilidad social ascendente y descendente en las clases medias argentinas: Un estudio comparativo. SIEMPRO. http://repositorio.cedes.org/handle/123456789/3853

Gordillo, G. (2020). Se viene el malón: Las geografías afectivas del racismo argentino. Cuadernos de Antropología Social, (52), 7-35. https://doi.org/10.34096/cas.i52.8899

Grahl, S. (2008). Las normas de excepción al ordenamiento urbano y territorial Relaciones de correspondencia entre los condicionantes históricos, geográficos y sociales [Tesis de doctorado, Universidad Nacional de La Plata]. SEDICI, Repositorio Institucional de la UNLP. http://sedici.unlp.edu.ar/bitstream/handle/10915/1795/Documento_completo_original.pdf

Grimson, A. (2019). ¿Qué es el peronismo? Siglo Veintiuno.

Guber, R. (1991). Villas miseria o cuando querer no es poder. In A. Gravano \& R. Guber (eds.), Barrio sí, villa también (pp. 13 - 62). CEAL.

Guber, R. (1996). Las manos de la memoria. Anuario Antropológico, (95), 191-221. https://doi.org/10.2307/3467400

Gutiérrez, L., \& Romero, L. (1994). Sectores populares, cultura y política: Buenos Aires en la entreguerra. Sudamericana.

Jelin, E. (1993). ¿Cómo construir ciudadanía? Una visión desde abajo. European Review of Latin American and Caribbean Studies, (55), 21-37.

Jelin, E., Vila, P., \& D’Amico, A. (1987). Podría ser yo los sectores populares urbanos en imagen y palabra. Ediciones de la Flor.

Kessler, G. (2016). Introducción. In G. Kessler (ed.), La sociedad argentina hoy. Radiografía de una nueva estructura (pp. 9-33). Siglo XXI.

Kessler, G., \& Di Virgilio, M. (2008). ¿Qué queda de la nueva pobreza? transformaciones en las últimas dos décadas. V Jornadas de Sociología de la UNLP, 10-12.12.2008, La Plata, Argentina. https://doi.org/10.18356/5a6a14fd-es

Martínez, J. (2007). 1977-2006: El ciclo de las reformas traumáticas. In M. López \& J. Waddel (eds.), Nueva historia del ferrocarril en la Argentina: 150 años de politica ferroviaria (pp. 209-292). Ediciones Lumiere. 
Masson, L. (2004). La política en femenino: Género y poder en la provincia de Buenos Aires. Antropofagia.

Merklen, D. (2005). Pobres Ciudadanos: Las clases populares en la era democrática, Argentina, 1983-2003. Gorla.

Míguez, D. \& Semán, P. (2006). Diversidad y recurrencia en las culturas populares actuales. In D. Míguez \& P. Semán (eds.), Entre santos, cumbias y piquetes. Las culturas populares en la Argentina reciente (pp. 11-32). Biblos.

Minujín, A. \& Kessler, G. (1995). La nueva pobreza en la Argentina. Planeta.

Minujín, A. \& López, N. (1994). Nueva pobreza y exclusión: El caso argentino. Nueva Sociedad, (131), 88-105.

Murmis, M., \& Portantiero, J. C. (1971). Estudios sobre los origenes del peronismo. Siglo XXI.

Pagano, F. (2017). La privatización y desguace del sistema ferroviario argentino durante el modelo de acumulación neoliberal. Jornadas de Sociología de la Facultad de Ciencias Políticas y Sociales de la UNCuyo, 15-16.06.2017, Mendoza. https://bdigital.uncu.edu.ar/10367

Quirós, J. (2006). Cruzando la Sarmiento. Una etnografía sobre piqueteros en la trama social del sur del Gran Buenos Aires. Antropofagia.

Ratier, H. (1971). El cabecita negra. Centro Editor de América Latina.

Roldán, D. (2008). La formación de los sectores populares urbanos en la historiografía argentina: Una mirada sobre el núcleo. Signos Históricos (20), 194-232

Segura, R. (2009). Si vas a venir a la villa, loco, entrá de otra forma: Distancias sociales, límites espaciales y efectos de lugar en un barrio segregado del gran Buenos Aires. In A. Grimson, C. Ferraudi Curto \& R. Segura (eds.), La vida politica en los barrios populares de Buenos. Aires (pp. 41-62). Prometeo.

Semán, P., \& Ferraudi Curto, C. (2016). Los sectores populares. In G. Kessler (ed.), La sociedad argentina hoy: Radiografia de una nueva estructura (pp. 141-162). Siglo XXI.

Svampa, M. (2005). La sociedad excluyente: La Argentina bajo el signo del neoliberalismo. Taurus.

Svampa, M. (ed.). (2009). Desde abajo: La transformación de las identidades sociales. Biblos.

Torrado, S. (ed.). (2010). El costo social del ajuste (Argentina 1976-2002). Edhasa.

Torre, J. C. (1990). La vieja guardia sindical y Perón: Sobre los orígenes del peronismo. Sudamericana.

Trovero, I. (2016). Clases sociales, movilidad social y sistemas de estratificación en los estudios empiricos de Gino Germani en Argentina (1955-1966): Una aproximación teórica a partir de una selección de textos clave. http://sedici.unlp.edu.ar/bitstream/handle/10915/60707/Documento_completo.pdf-PDFA.pdf?sequence=1\&isAllowed=y

Visacovsky, S. (2008). Estudios sobre clase media en la antropología social: Una agenda para la Argentina. Avá, (13), 9-37.

Visacovsky, S., \& Garguin, E. (eds.). (2009). Moralidades, economías e identidades de clase media: Estudios históricos y etnográficos. Antropofagia.

Vommaro, G., \& Gené, M. (2017). Argentina: El año de Cambiemos. Revista de ciencia política, 37(2), 231-254. https://doi.org/10.4067/s0718-090x2017000200231

Vommaro, G., \& Quirós, J. (2011). “Usted vino por su propia decisión”: Repensar el clientelismo en clave etnográfica. Desacatos, (36), 65-84. 